\title{
A stochastic rough-approximation water management model for supporting sustainable water-environment strategies in an irrigation district of arid region
}

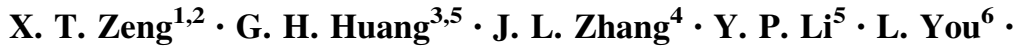 \\ Y Chen ${ }^{1} \cdot$ P. P. Hao ${ }^{1}$
}

Published online: 17 August 2017

(C) Springer-Verlag GmbH Germany 2017

\begin{abstract}
In this study, a stochastic rough-approximation water management model (SRAWM) associated with optimistic and pessimistic options is proposed for supporting regional sustainability in an irrigation system (IS) of an arid region with uncertain information. SRAWM can not only handle conventional stochastic variations in objective functions or constraints, but also tackle objective and subjective (i.e., risk performance of the decision maker) fuzziness through rough-approximation model based on measure Me. The developed model would be applied to a real case study of an irrigation district (ID) in Kaidu-kongque River Basin, China, which is encountering challenges in economic development and a serious environmental crisis (e.g., drought, water deficit, land deterioration, stalinization, soil erosion and water pollution) synchronously. Simulation technical (i.e., support vector regression) is put into SRAWM framework to reflect dynamic prediction of water demand in the future. Results of optimized irrigation area, water allocation, water deficit,
\end{abstract}

G. H. Huang

huangg@uregina.ca

1 Capital University of Economics and Business, Beijing 100070, China

2 Institute for Energy, Environment and Sustainable Communities, University of Regina, Regina, SK S4S 0A2, Canada

3 Faculty of Engineering and Applied Sciences, University of Regina, Regina, SASK S4S 0A2, Canada

4 College of Environmental Science and Engineering, Qingdao University, Qingdao, Shandong 266071, China

5 Beijing Normal University, Beijing 100048, China

6 Research Center for Eco-Environmental Sciences, Chinese Academy of Sciences, Beijing 100085, China pollution reduction, water and soil erosion and system benefit under various water-environmental policies (corresponding to various ecological effects) are obtained. Tradeoffs between ecological and irrigative water usages can facilitate the local decision makers rectifying the current irrigation patterns and ecological protection polices. Moreover, compromises between systemic benefit and failure risk can help policymakers to generate a robust riskcontrol plan under uncertainties. These detections are beneficial to achieve conjunctive goals of socio-economic development and eco-environmental sustainability in such an arid IS.

Keywords Rough-approximation · Stochastic programming · Support-vector-regression (SVR) .

Irrigation system (IS) · Uncertainty · Risk sensitive analysis

\section{List of symbols}

$f \quad$ System benefit from an ecological irrigation system (US \$)

$B_{m j}^{A} \quad$ Net benefit for agricultural crop in district j per volume of water being delivered (US $\$ / \mathrm{m}^{3}$ )

$D A_{m j} \quad$ Irrigation area target for agricultural crop in district $\mathrm{j}$ (ha)

$R A_{m j} \quad$ Water consumption per unit area for agricultural crop in district $\mathrm{j}\left(\mathrm{m}^{3} / \mathrm{ha}\right)$

$S A_{k m j} \quad$ Water shortage for agricultural plant $\mathrm{n}$ in district $\mathrm{j}$ $\left(\mathrm{m}^{3}\right)$

$C_{m j}^{A} \quad$ Loss of water shortage for agricultural plant in district $\mathrm{j}$ per volume of water not being delivered (US $\$ / \mathrm{m}^{3}$ )

$B_{n j}^{E} \quad$ Net benefit for ecological plant in district j per volume of water being delivered (US $\$ / \mathrm{m}^{3}$ )

$D E_{n j} \quad$ Planting area target for ecological plant in district j (ha) 
$R E_{n j} \quad$ Water consumption per unit area for ecological plant in district $\mathrm{j}\left(\mathrm{m}^{3} / \mathrm{ha}\right)$

$S E_{k n j} \quad$ Water shortage for ecological plant $\mathrm{n}$ in district $\mathrm{j}\left(\mathrm{m}^{3}\right)$

$C_{n j}^{E} \quad$ Loss of water shortage for ecological plant in district $\mathrm{j}$ per volume of water not being delivered (US $\$ / \mathrm{m}^{3}$ )

$B_{j}^{M} \quad$ Net benefit for farmer living water in district $\mathrm{j}$ per volume of water being delivered (US $\$ / \mathrm{m}^{3}$ )

$C_{k m j}^{A} \quad$ Loss of water shortage for agricultural crop m in district $\mathrm{j}$ per volume of water not being delivered (US $\$ / \mathrm{m}^{3}$ )

$F_{n j}^{E C} \quad$ Net benefits from pollution discharges retreated through ecological mechanism in district $\mathrm{j}$ (US $\$ / \mathrm{m}^{3}$ )

$T_{n j}^{E C} \quad$ Water delivering costs for ecological plant in district $\mathrm{j}$ volume of water being polluted (US $\$ / \mathrm{m}^{3}$ )

$F_{n j}^{E C S} \quad$ Net benefits from soil intention through ecological mechanism in district $\mathrm{j}$ (US $\$ / \mathrm{m}^{3}$ )

$F_{n j}^{E C W} \quad$ Net benefits from water conservation through ecological mechanism in district $\mathrm{j}$ (US $\$ / \mathrm{m}^{3}$ )

$T_{m j}^{A C} \quad$ Water delivering costs for agricultural crop in district $\mathrm{j}$ volume of water being polluted (US $\$ / \mathrm{m}^{3}$ )

$F_{m j}^{A C} \quad$ Pollution discharge treatment costs for agricultural crop in district $\mathrm{j}$ volume of water being polluted (US $\$ / \mathrm{m}^{3}$ )

$F_{m j}^{A C S} \quad$ Soil intention costs for agricultural crop in district j volume of water being polluted (US $\$ / \mathrm{m}^{3}$ )

$F_{m j}^{A C W} \quad$ Water conservation costs for agricultural crop in district $\mathrm{j}$ volume of water being polluted (US $\$ / \mathrm{m}^{3}$ )

$S M_{k j} \quad$ Water shortage for farmer living water in district $\mathrm{j}$ $\left(\mathrm{m}^{3}\right)$

$C_{j}^{M} \quad$ Loss of water shortage for farmer living water in district $\mathrm{j}$ per volume of water not being delivered (US $\$ / \mathrm{m}^{3}$ )

$T_{j}^{M C} \quad$ Water delivering costs for farmer living water in district $\mathrm{j}$ volume of water not being polluted (US $\$ / \mathrm{m}^{3}$ )

$F_{j}^{M C} \quad$ Environmental treatment costs for farmer living water in district $\mathrm{j}$ volume of water not being polluted (US $\$ / \mathrm{m}^{3}$ )

$p_{h j} \quad$ Probability of random water availability $Q_{i j}^{ \pm}$ under level h (\%)

$Q_{k j} \quad$ Water availability from river and underground of district $\mathrm{j}$ under probability $p_{j}\left(\mathrm{~m}^{3}\right)$

$R_{k j} \quad$ Water flow from river of district $\mathrm{j}$ in period $\mathrm{t}$ under probability $p_{j}\left(\mathrm{~m}^{3}\right)$

$E_{j} \quad$ Evaporation and infiltration loss of water from river of district $\mathrm{j}\left(\mathrm{m}^{3}\right)$

$H_{j} \quad$ Normal water requirement of watercourse of district $\mathrm{j}\left(\mathrm{m}^{3}\right)$

$Q U_{j} \quad$ Water availability from underground water of district $\mathrm{j}\left(\mathrm{m}^{3}\right)$

$A X M_{j} \quad$ The minimum water demand for farmer living water in district $\mathrm{j}\left(\mathrm{m}^{3}\right)$
$X D A_{m j} \quad$ The maximum land utilization area for agricultural crop in district $\mathrm{j}$ (ha)

$X D E_{n j} \quad$ The maximum land utilization area for ecological plant in district $\mathrm{j}$ (ha)

$S C M_{h j}$ The maximum water supply capacity in district $\mathrm{j}$ under level $\mathrm{h}\left(10^{6} \mathrm{~m}^{3}\right)$

$E A_{m j} \quad$ The maximum soil erosion for agricultural crop in district $\mathrm{j}$ (ton)

$E E_{n j} \quad$ The maximum soil erosion for ecological plant in district $\mathrm{j}$ (ton)

$N A_{m j} \quad$ Nitrogen discharge for agricultural crop in district j per unit water consumption (ton $/ \mathrm{m}^{3}$ )

$P A_{m j} \quad$ Phosphorus discharge for agricultural crop in district $\mathrm{j}$ per unit water consumption (ton $/ \mathrm{m}^{3}$ )

$B A_{m j} \quad$ BOD discharge for agricultural crop in district $\mathrm{j}$ per unit water consumption (ton $/ \mathrm{m}^{3}$ )

$\gamma_{N} \quad$ The purification capacity coefficient of Nitrogen discharge for ecological plant in district $j$ per unit water consumption (ton $/ \mathrm{m}^{3}$ )

The purification capacity coefficient of Phosphorus discharge for ecological plant in district $\mathrm{j}$ per unit water consumption $\left(\mathrm{ton} / \mathrm{m}^{3}\right)$ The purification capacity coefficient of BOD discharge for ecological plant in district $\mathrm{j}$ per unit water consumption (ton $/ \mathrm{m}^{3}$ )

$\alpha_{m j} \quad$ The erosion coefficient for agricultural crop in district $\mathrm{j}$ per unit water consumption

$\beta_{n j} \quad$ The erosion coefficient for ecological plant in district $\mathrm{j}$ per unit water consumption

$N M_{j} \quad$ Nitrogen discharge for farmer living water in district $\mathrm{j}$ per unit water consumption $\left(\mathrm{ton} / \mathrm{m}^{3}\right)$

$P M_{j} \quad$ Phosphorus discharge for farmer living water in district $\mathrm{j}$ per unit water consumption (ton $/ \mathrm{m}^{3}$ )

$B M_{j} \quad$ BOD discharge for farmer living water in district j per unit water consumption (ton $/ \mathrm{m}^{3}$ )

$N A P_{j} \quad$ The maximum nitrogen discharge in district $\mathrm{j}$ per unit water consumption (ton $/ \mathrm{m}^{3}$ )

$P A P_{j} \quad$ The maximum phosphorus discharge in district $\mathrm{j}$ per unit water consumption ( $\mathrm{ton} / \mathrm{m}^{3}$ )

$B A P_{j} \quad$ The maximum BOD discharge in district $\mathrm{j}$ per unit water consumption (ton $/ \mathrm{m}^{3}$ )

\section{Subscript}

j District: $\mathrm{j}=1$ Kuerle, $\mathrm{j}=2$ Yanqi, $\mathrm{j}=3$ Hejing, $\mathrm{j}=4$ Heshuo, $\mathrm{j}=5$ Bohu $\mathrm{j}=6$ Luntai and $\mathrm{j}=7$ Yuli

$\mathrm{m}$ Agriculture crop: $\mathrm{m}=1$ Wheat, $\mathrm{m}=2$ Cotton, $\mathrm{m}=3$ Oil plants, $\mathrm{m}=4$ Vegetable

$\mathrm{n}$ Ecological plant: $\mathrm{n}=1$ Medicago, $\mathrm{n}=2$ Populus, $\mathrm{n}=3$ Tarmaik, $\mathrm{n}=4$ Alhagl, $\mathrm{n}=5$ other,

$\mathrm{k}$ Water level: $\mathrm{k}=1$ Low, $\mathrm{k}=2$ Medium, $\mathrm{k}=3$ High 


\section{Introduction}

In the past half century agricultural development has greatly increased global food supply but often with detrimental effects on the environment (Tilman et al. 2002). Particular in some arid regions, excessive exploration of human activity and overexpansion of cultivation have brought about numbers of environmental detriments such as water deficit, water pollution, land deterioration, stalinization and soil erosion, leading a water-environment crisis (Wei et al. 2010). The negative influences of extravagant cultivation and fertilization in a arid irrigation district (AID) can be reversed through ecological activities, which can reduce pollution discharges, avail soil/water conservation, alleviate stalinization and prevent desertification (Mohammad and Adam 2010; Lopez-Pomares et al. 2015). However, competitive relationship in water consumption between agriculture activity and ecological protection would restrict the exertion of ecological function in an AID (Mohammad and Adam 2010; Lopez-Pomares et al. 2015). Therefore, an appropriate water management plan integrating irrigation and environmental policies with consideration of ecological effect is required, which can promote integrality of regional economic development and environmental sustainability synchronously.

However, an irrigation system (IS) is complicated with a variety of uncertainties incorporating with objective and subjective conditions (Huang and Loucks 2000; Li et al. 2006; Wen and Iwamura 2008; Zeng et al. 2014). Previously, many researchers have developed optimization methods to plan irrigation to handle inherent uncertainties in decisionmaking processes, particular for objective conditions (Doron Lavee 2010; Li et al. 2013; Bekri et al. 2015). For example, spatial and temporal variations such as stream flows for irrigation and their frequencies of peaks are deemed as stochastic factors, which fluctuations can be associated with the net system benefits; these uncertainties can be handled by stochastic programming (SP) ( $\mathrm{Li}$ et al. 2006; Zeng et al. 2015). However, in a practical irrigation planning issue, the input information such as loss for water deficit and cost for water delivering are often difficult to obtain accurately; meanwhile, diffusion and migration of pollution from farm fertilization are very special and complex, which can not be provided as a precise value for decision maker usually. Therefore, fuzzy programming (FP) is adopted to describe this fuzziness of observed information, which can tackle vagueness in goals or constraints caused by inartificial imprecision/vagueness (Liu and Liu 2002).

Nevertheless, pessimistic-optimistic attitudes are often existed in a fuzzy decision-making process, which can not be tackled by conventional FP (Wen and Iwamura 2008; $\mathrm{Xu}$ and Zhou 2013). Therefore, an advanced measure Me is introduced, which can reflect compromise stroked by optimistic and pessimistic option in the decision process with uncertain information (Lau et al. 2010). In general, measure Me can evaluate the ambiguity of optimisticpessimistic attitude to an interval value through introducing an optimistic-pessimistic adjusting factor ( $\mathrm{Xu}$ and Zhou 2013). However, this optimistic-pessimistic interval value expressed as a certain shadow of the original feasible region can not reflect total possible situation due to mixed fuzziness (concluding inartificial and artificial fuzziness). For the sake of simulating the feasible region more succinctly, rough set theory (RST) is introduced to describe the vagueness through two approximation value models (i.e., the lower/upper approximation value model), which can generate a more accessible result for decision maker (Pawlak 1998).

Although the above optimization method can deal with objective and subjective uncertainties in an IS, they encounter challenge that more accurate prediction would be required based on fragmentary input data. For example, a number of system components deemed as impact factors can affect prediction of water demand, which would mislead the results of optimization due to low accuracy. Meanwhile low accuracy of prediction may enhance the complexities of decision-making, as well as fortifying the risks for decision makers (Steffens et al. 2012). Therefore, an accurate prediction method named support vector regression (SVR) is introduced to tackle problems with the characters of small samples, nonlinearity, high dimension, and local minima (Vapnik 1998; Smola and Schölkopf 2000; Noori et al. 2009; Dai et al. 2011; Zeng et al. 2015). Though SVR technique has been applied to numbers of realistic water planning problems proverbially, few studies pay close attention to the application of SVR for ecological irrigative water planning under uncertainties in an arid IS.

Therefore, the aim of this study is developing a stochastic rough-approximation water management model (SRAWM) associated with optimistic and pessimistic options for IS, through incorporating SP and FP within a general frame. The proposed method can handle vagueness through approximation models; it can also reflect fuzziness compromising optimistic and pessimistic options in a decision-making process through measure Me. The SRAWM method will be applied to a real case study of irrigation district in Kaidu-Kongque River Basin, where can counter the challenges of accelerated exploration and cultivation, and serious environmental crisis (e.g., water deficit, land deterioration, stalinization, soil erosion and water pollution) in northwestern China. Simulation technical (i.e., SVR) is imported into SRAWM framework to predict the prospective irrigation and ecological water demands interactively and dynamically. The results of 
various water management plans and environmental policies (ecological effects) can be analyzed. The results can be used for rectifying current irrigation patterns and environmental protection measures to satisfy socio-economic development and eco-environmental sustainability.

\section{Stochastic rough-approximation water management model (SRAWM)}

In a conventional irrigation planning problem, the decision maker is responsible for allocating water to multiple agricultural crops, with the aim to maximize system benefits (e.g., economic, environmental and social benefits) based on limited water. Based on local policies, the promised water is delivered to crops, which bring about benefits to economy; otherwise, crop would obtain water from more expensive sources or afford economic penalties. In such a problem, the water availability expressed as random variable (secondstage decision) would rectify the water-allocation target (first stage decision). Thus, a two-stage stochastic programming (TSP) model is as follows ( $\mathrm{Li}$ et al. 2006):

Max $f=\sum_{i=1}^{I} c_{i} e_{i} x_{i}-\sum_{h=1}^{H} \sum_{i=1}^{I} p_{h i} d_{i} e_{i} y_{h i}$

subject to

$\sum_{h=1}^{H} \sum_{i=1}^{I}\left(x_{i}-y_{h i}\right) e_{i} \leq Q_{h i}$

$y_{h i} \leq x_{i} \leq x_{\text {imax }}, i=1,2, \ldots, I ; h=1,2, \ldots, H$

$x_{i} \geq 0, i=1,2, \ldots, I$

$y_{i h} \geq 0, i=1,2, \ldots, I ; h=1,2, \ldots, H$

where $f$ is the system benefit (\$); i denotes type of crop ( $\mathrm{i}=1,2, \ldots, \mathrm{I})$; $\mathrm{h}$ denotes probability level of random water availability $(\mathrm{h}=1,2, \ldots, \mathrm{H}) ; c_{i}$ is net benefit for crop i per volume of water being delivered $\left(\$ / \mathrm{m}^{3}\right) ; e_{i}$ is irrigation quota, which presents water consumption per area for crop i $\left(\mathrm{m}^{3} /\right.$ ha). $x_{i}$ is irrigated area target of crop i (ha); $Q_{h i}$ is total water availability under probability $p_{h i}\left(\mathrm{~m}^{3}\right) ; p_{h i}$ denotes probability of random water availability $Q_{h i}$ under level h $(\%) ; d_{i}$ is economic loss of water shortage for crop i $\left(\$ / \mathrm{m}^{3}\right) ; y_{h i}$ is water deficiency area for crop i when demand is not met (ha). The first-stage benefits (i.e., $\sum_{i=1}^{I} c_{i} e_{i} x_{i}$ ) can be rectified by the second-stage penalties $\left(\sum_{h=1}^{H} \sum_{i=1}^{I} p_{h i} d_{i} e_{i} y_{h i}\right)$ (Li et al. 2006). In general, the first-stage variable $x_{i}$ should be greater than second-stage variable $y_{h i}$; meanwhile, it should be smaller than the maximum irrigative area that can be regulated by policymakers (i.e., $x_{i \max }$ ).

However, when uncertainties are expressed as possibility distributions in the ambiguous coefficients of objective function, fuzzy set theory has been introduced (Zadeh 1965). Based on the concepts of fuzzy set theory, possibility and necessity measures are introduced as follows:

$\operatorname{Pos}\{\xi \leq r\}=\sup _{u \leq r} \mu(u)$
$\operatorname{Nec}\{\xi \leq r\}=1-\sup _{u>r} \mu(u)$

where $\xi$ would be a fuzzy variable with membership function $\mu$, meanwhile $\mathrm{u}$ and $\mathrm{r}$ would be real numbers (Trumbo and Mccomas 2003). In fact, the possibility measure is defined as: $\operatorname{Pos}\{\xi \leq r\}$, which present the possibility of the fuzzy event occurrence; The necessity of this fuzzy event is defined as the impossibility of the opposite event is defined as $N e c\{\xi \leq r\}$. However, measures Pos and $\mathrm{Nec}$ are limited to handle realistic fuzziness of decision makers' risk performance (Xu and Zhou 2013). Therefore, an optimistic-pessimistic parameter is introduced to express different optimistic-pessimistic attitudes of decision makers according to their own experiences and judgments. Let measure Nec would be the reference measure expressed as pessimistic attitude, meanwhile introducing a optimisticpessimistic adjusting factor $(\lambda)$, thus, a new measure Me can be expressed as follows (Xu and Zhou 2013):

$\operatorname{Me}\{\xi \leq r\}=\operatorname{Nec}\{\xi \leq r\}+\lambda(\operatorname{Pos}\{\xi \leq r\}-\operatorname{Nec}\{\xi \leq r\})$

where $\lambda(0 \leq \lambda \leq 1)$ is the optimistic-pessimistic parameter to determine the combined attitude of a decision maker. Model (3) can evaluate the degree that a fuzzy variable takes the values in an interval with different optimistic-pessimistic attitudes based on the convex combination of Pos and $\mathrm{Nec}$ (i.e., $N e c\{\xi \leq r\}+\lambda(\operatorname{Pos}\{\xi \leq r\}-N e c\{\xi \leq r\}))$. Therefore, a stochastic approximation with optimistic and pessimistic option method (SAOP) can be shown as follows:

$\operatorname{Max} f=e_{i}\left(\sum_{i=1}^{I} \tilde{c}_{i} x_{i}-\sum_{h=1}^{H} \sum_{i=1}^{I} p_{h i} \tilde{d}_{i} y_{h i}\right)$

subject to

$$
\begin{aligned}
& M e\left\{\sum_{h=1}^{H} \sum_{i=1}^{I} e_{i}\left(x_{i}-y_{h i}\right) \leq \tilde{Q}_{h i}\right\} \geq \delta_{r}, i=1,2, \ldots, I \\
& \quad h=1,2, \ldots, H ; r=1,2, \ldots, R\} \\
& y_{h i} \leq x_{i} \leq x_{i \max }, i=1,2, \ldots, I ; h=1,2, \ldots, H \\
& x_{i} \geq 0, i=1,2, \ldots, I \\
& y_{i h} \geq 0, i=1,2, \ldots, I ; h=1,2, \ldots, H
\end{aligned}
$$


where $\delta_{r}(r=1,2, \ldots, R)$ are the decision maker's confidence levels, which contain the information with a determined optimistic-pessimistic attitude of decision maker. Let $\tilde{\xi}=\left(\xi_{1}, \xi_{2}, \xi_{3}\right)$ be a triangular fuzzy number. According to Eq. (2), the expected value of $\tilde{\xi}$ is $\left(\xi_{1}, \xi_{2}, \xi_{3}\right) / 3$ and the corresponding measure Me are as follows:

$\operatorname{Me}\{\tilde{\xi} \geq r\}= \begin{cases}1 & \text { if } r \leq \xi_{1}, \\ \lambda+(1-\lambda) \frac{\xi_{2}-r}{\xi_{2}-\xi_{1}} & \text { if } \xi_{1} \leq r \leq \xi_{2}, \\ \lambda \frac{\xi_{3}-r}{\xi_{3}-\xi_{2}} & \text { if } \xi_{2} \leq r \leq \xi_{3}, \\ 0 & \text { if } r \leq \xi_{3},\end{cases}$

Then, the objective function of triangular fuzzy variable $\tilde{\xi}=\left(\xi_{1}, \quad \xi_{2}, \quad \xi_{3}\right)$ can be expressed as follows:

$f(\tilde{\xi})= \begin{cases}\frac{\lambda}{2} \xi_{1}+\frac{1-\lambda}{2} \xi_{3}+\frac{1}{2} \xi_{2} & \text { if } \xi_{3} \leq 0, \\ \frac{\lambda}{2}\left(\xi_{2}+\xi_{1}\right)+\frac{\lambda \xi_{3}^{2}-(1-\lambda) \xi_{2}^{2}}{2\left(\xi_{3}-\xi_{2}\right)} & \text { if } \xi_{2} \leq 0 \leq \xi_{3}, \\ \frac{(1-\lambda) \xi_{2}^{2}-\lambda \xi_{1}^{2}}{2\left(\xi_{2}-\xi_{1}\right)}+\frac{\lambda}{2}\left(\xi_{2}+\xi_{3}\right) & \text { if } \xi_{1} \leq 0 \leq \xi_{2}, \\ \frac{1-\lambda}{2} \xi_{1}+\frac{1}{2} \xi_{2}+\frac{\lambda}{2} \xi_{3} & \text { if } 0 \leq \xi_{1},\end{cases}$

Let $\mathrm{V}$ be a finite and non-empty set, and let $\mathrm{W}$ be an equivalence relation on $\mathrm{V}$. $\mathrm{V} / \mathrm{W}$ can be denoted as the family of all the equivalence classes of $\mathrm{W}$ (or classifications of $\mathrm{V}$ ), and $[x]_{W}$ can be denoted as an equivalence class in $\mathrm{W}$ containing an element $x \in V$. Let $\mathrm{V}$ be the universe and let $\mathrm{W}$ be an equivalence relation on $\mathrm{V}$. For any subset $X \subset V$, the pair $S=(V, W)$ is called an approximation space (Xu and Zhou 2013). The two subsets are as follows:

$W \underline{X}=\left\{x \in V \mid[x]_{W} \subseteq V\right\}$

$W \bar{X}=\left\{x \in V \mid[x]_{W} \cap V \neq \emptyset\right\}$

Model (7a) and (7b) are called the W-lower and W-upper approximations of $\mathrm{X}$, where $W X=(W \underline{X}, W \bar{X})$ are obtained. Let $P=\left\{(x, \xi) \mid \operatorname{Pos}\left\{g_{r}(x, \xi) \leq 0\right\} \geq \delta_{r}\right\}$ (where $\mathrm{P}$ is the universal) and $N=\left\{(x, \xi) \mid N e c\left\{g_{r}(x, \xi) \leq 0\right\} \geq \delta_{r}\right\}$, we have:

$$
\begin{aligned}
N & \subseteq X \subseteq P \Rightarrow\left\{\operatorname{Nec}\left\{g_{r}(x, \xi) \leq 0\right\} \leq\left\{\operatorname{Me}\left\{g_{r}(x, \xi) \leq 0\right\}\right.\right. \\
& \leq\left\{\operatorname{Pos}\left\{g_{r}(x, \xi) \leq 0\right\}\right.
\end{aligned}
$$

Based on Model (4a), using the $\alpha$-level set of fuzzy variable of $\tilde{Q}_{h i}$ as $\left[Q_{h i}^{L}, Q_{h i}^{R}\right]$, thus, corresponding Pos and $\mathrm{Nec}$ can be rewritten as:

$$
\begin{gathered}
\operatorname{Pos}\left\{\sum_{h=1}^{H} \sum_{i=1}^{I} e_{i}\left(x_{i}-y_{h i}\right) \leq \tilde{Q}_{h i}\right\} \geq \delta_{r} \\
\Leftrightarrow \sum_{h=1}^{H} \sum_{i=1}^{I} e_{i}\left(x_{i}-y_{h i}\right) \leq Q_{h i}^{R-\alpha} \\
\operatorname{Nec}\left\{\sum_{h=1}^{H} \sum_{i=1}^{I} e_{i}\left(x_{i}-y_{h i}\right) \leq \tilde{Q}_{h i}\right\} \geq \delta_{r} \\
\Leftrightarrow \sum_{h=1}^{H} \sum_{i=1}^{I} e_{i}\left(x_{i}-y_{h i}\right) \leq Q_{h i}^{L-(1-\alpha)}
\end{gathered}
$$

Since $\tilde{Q}_{h i}$ are LR fuzzy variables, the membership function of them are as follows:

$\mu_{Q_{h i}}(t)= \begin{cases}L\left(\frac{Q_{h i}-t}{\delta_{r}^{L}}\right), & t \leq Q_{h i} \\ R\left(\frac{t-Q_{h i}}{\delta_{r}^{R}}\right), & t \geq Q_{h i}\end{cases}$

where the mean value $\delta_{r}^{L}$ and $\delta_{r}^{R}$ are left and right spreads of $Q_{h i}$. The reference functions L, R: $[0,1] \rightarrow[0,1]$ satisfy $\mathrm{L}(1)=\mathrm{R}(1)=0, \quad \mathrm{~L}(0)=\mathrm{R}(0)=1$. Suppose $Q_{h i}$ are independent, then:

$$
\begin{gathered}
\operatorname{Pos}\left\{\sum_{h=1}^{H} \sum_{i=1}^{I} e_{i}\left(x_{i}-y_{h i}\right) \leq \tilde{Q}_{h i}\right\} \geq \delta_{r} \\
\Leftrightarrow\left(1-\delta_{r}\right) Q_{h i r} \geq e_{i r}\left(x_{i}-y_{h i}\right)
\end{gathered}
$$

$$
\begin{gathered}
N e c\left\{\sum_{h=1}^{H} \sum_{i=1}^{I} e_{i}\left(x_{i}-y_{h i}\right) \leq \tilde{Q}_{h i}\right\} \geq \delta_{r} \\
\Leftrightarrow Q_{h i r}+\left(1-\delta_{r}\right) Q_{h i r} \geq e_{i r}\left(x_{i}-y_{h i}\right)
\end{gathered}
$$

Let $\underline{X}=N$ and $\bar{X}=P$, we use $\underline{X}$ and $\bar{X}$ to approximate $X$, it is apparent that $\underline{X} \subseteq X \subseteq \bar{X}$. Based on Model (4), we assume that $\tilde{c}_{i}=\left(\underline{c}_{i}, \quad c_{i}, \quad \bar{c}_{i},\right), \tilde{d}_{i}=\left(\underline{d}_{i}, \quad d_{i}, \bar{d}_{i},\right)$ are positive triangular fuzzy variables. Then a stochastic rough-approximation water management model (SRAWM) can be transferred can be transformed into two models (the lower and upper approximation value model (LAV and UAV)) as follows:

$$
\begin{aligned}
\text { Max } & f^{L A V}=\sum_{i=1}^{I}\left[\frac{1-\lambda}{2}\left(\underline{c}_{i}-c_{i}\right)+\frac{c_{i}}{2}+\frac{\lambda}{2}\left(\bar{c}_{i}+c_{i}\right)\right] e_{i} x_{i} \\
- & \sum_{i=1}^{I} \sum_{h=1}^{H} p_{h i}\left[\frac{1-\lambda}{2}\left(\underline{d}_{i}-d_{i}\right)+\frac{d_{i}}{2}+\frac{\lambda}{2}\left(\bar{d}_{i}+d_{i}\right)\right] e_{i} y_{h i}
\end{aligned}
$$

subject to

$$
\begin{aligned}
\left(1-\delta_{r}\right) Q_{h i r} \geq e_{i r}\left(x_{i}-y_{h i}\right), r & =1,2, \ldots, p ; i \\
& =1,2, \ldots, I ; h=1,2, \ldots, H
\end{aligned}
$$




$$
\begin{aligned}
y_{h i} \leq x_{i} \leq x_{i \max }, i=1,2, \ldots, I ; h=1,2, \ldots, H & (10 \mathrm{c}) \\
x_{i} \geq 0, i=1,2, \ldots, I & (10 \mathrm{~d}) \\
y_{i h} \geq 0, i= & 1,2, \ldots, I ; h=1,2, \ldots, H \\
\operatorname{Maxf}^{U A V}= & \sum_{i=1}^{I}\left[\frac{1-\lambda}{2}\left(\underline{c}_{i}-c_{i}\right)+\frac{c_{i}}{2}+\frac{\lambda}{2}\left(\bar{c}_{i}+c_{i}\right)\right] e_{i} x_{i} \\
& -\sum_{i=1}^{I} \sum_{h=1}^{H} p_{h i}\left[\frac{1-\lambda}{2}\left(\underline{d}_{i}-d_{i}\right)+\frac{d_{i}}{2}+\frac{\lambda}{2}\left(\bar{d}_{i}+d_{i}\right)\right] e_{i} y_{h i}
\end{aligned}
$$

subject to

$$
\begin{aligned}
& Q_{h i r}+\left(1-\delta_{r}\right) Q_{h i r} \geq e_{i r}\left(x_{i}-y_{h i}\right), r=1,2, \ldots, p ; i \\
& \quad=1,2, \ldots, I ; h=1,2, \ldots, H \\
& y_{h i} \leq x_{i} \leq x_{i \max }, i=1,2, \ldots, I ; h=1,2, \ldots, H \\
& x_{i} \geq x_{i}^{L A M} \geq 0, i=1,2, \ldots, I \\
& y_{i h}^{L A M} \geq y_{i h} \geq 0, i=1,2, \ldots, I ; h=1,2, \ldots, H
\end{aligned}
$$

Through solving model (9) to (10), multiple uncertainties (including inartificial and artificial uncertainties) presented as fuzziness that exist in constraints and objective function can be handled.

\section{Water resources management in Kaidu- Kongque ecological irrigation district}

\subsection{The study area}

Kaidu-Kongque River Basin $\left(71^{\circ} 39^{\prime}{ }^{\prime} \mathrm{E}-93^{\circ} 45^{\prime} \mathrm{E}\right.$, $34^{\circ} 20^{\prime \prime} \mathrm{N}-43^{\circ} 39^{\prime \prime} \mathrm{N}$ ) located in the middle of the Tarim River Basin is important region of cotton and grain production in the Bayangol Mongol autonomous prefecture of Xinjiang Uygur autonomous region, northwest China (SYXUAR 2010). The basin includes seven counties and covers approximately $62,000 \mathrm{~km}^{2}$, which is suitable for the growth of the crops (e.g., wheat, corn, oil plant, tomato, and fruit). In study region, more than $95 \%$ of the arable land requires irrigation; meanwhile, about $92 \%$ of the total water-resources are contributed by agricultural irrigation (Huang et al. 2013). But in reality, the region has characteristics of drought: little precipitation and intensive evaporation, which have restricted the development of irrigation. For example, the annual precipitations in most of Uygur autonomous region are usually from 90 to $150 \mathrm{~mm}$, however the extreme situation in Luntai county is less than $20 \mathrm{~mm}$. The high evaporation is about is from 1157 to $1512 \mathrm{~mm} /$ year, which has aggravated the aridity in study region. Such climatic conditions would result in not only severe deficit in the irrigation district, but also devastating blow to agriculture (Huang et al. 2013). Particular in recent years, population has presented an increasing trend, which reached 1.3 million (SYXUAR 2013). The increasing requirement of food safety has accelerated exploitation of cultivation, as well as improving efficiency of irrigation. Thus, the decision makers would face tremendous challenges as follows: (a) Increasing of agriculture production based on food security would result in over-expansion of cultivation. Over exploitation and utilization can destroy the original balance structure of land, leading land deterioration. (b) Water demand of irrigation present a rising tendency, which would excess the limits of what the natural system can provide. Therefore, overquick development of economy can enhance pressure of water resources usage, leading heavier risk of water deficit. (c) Excessive farming cultivation/fertilization can bring about serious water pollution, which would shrunk available water resource to aggravate water shortage. Under these situations, an effective manner should to be advocated with consideration of balancing the relationship between development of economy and sustainability of environment.

Figure 1 shows that, in an IS, irrigation and ecological activity are coupled into a framework, where negative influences of the conventional irrigation system (e.g., excessive nitrogen/phosphorus discharges) can be converted through the ecological function. However, they are competitor in water consumptions. Under these situations, a sound water-resources planning become a key to remit contradiction between economic development and environmental protection of this arid region, which can optimize the water for exploitation and utilization under limited water resources on one hand, and also concern the deterioration of environment on another (Huang et al. 2013). However, temporal variations such as available water resources and fuzzy input data such as economic data can vary the optimal schemes for an effective irrigation, which may fortify complexities of relevant water allocation optimization and thus the associated decision (Li and Huang 2011). An advanced optimization model (i.e., a stochastic rough-approximation water management model with optimistic and pessimistic option method (SRAWM)) can be developed for allocating water resource in an IS with a more efficient manner. 


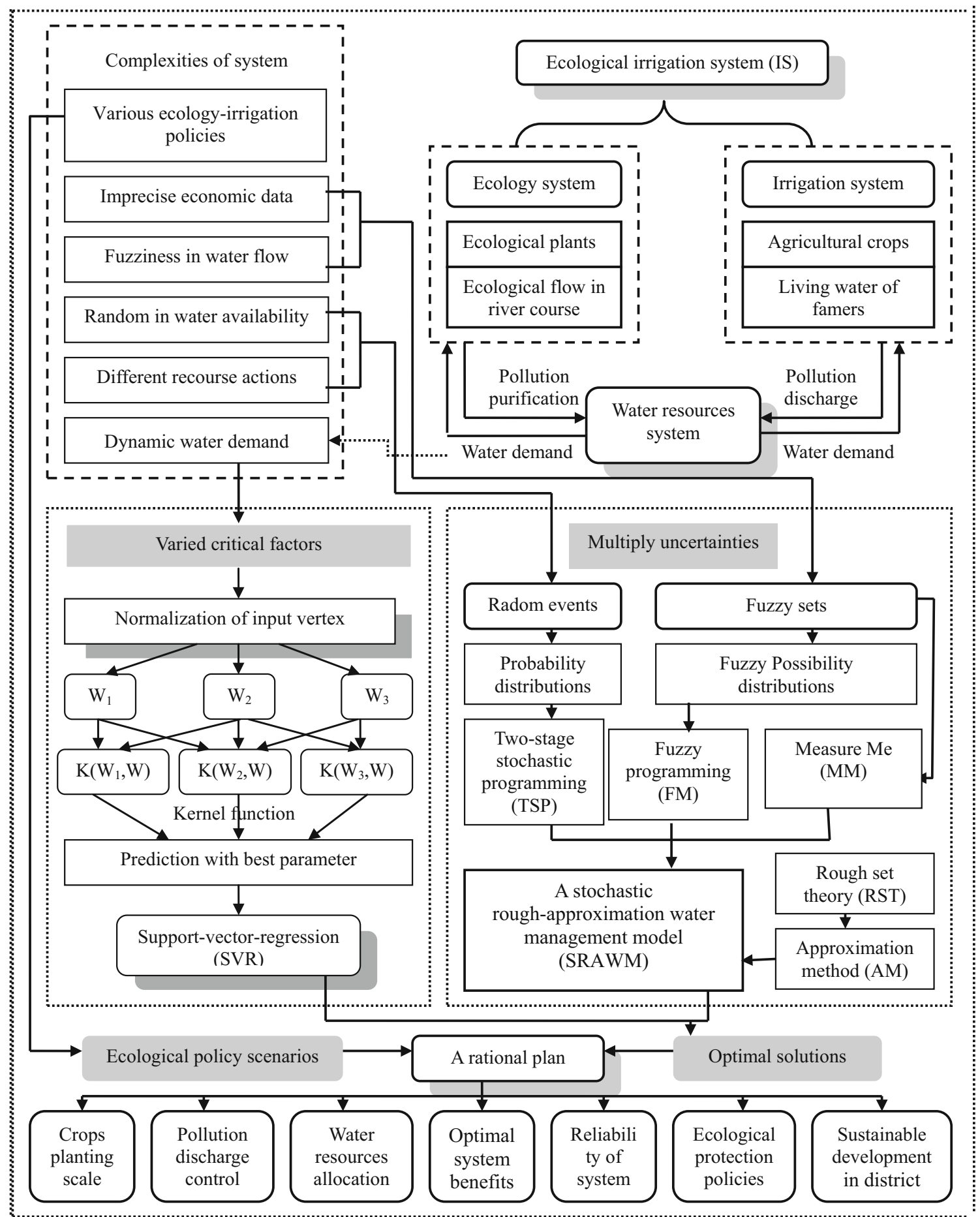

Fig. 1 Framework of SRAWM method application of Kaidu-kongque ecological irrigation district

\subsection{Modeling formulation}

In study region, the irrigation district is extremely vulnerable to disturbance and habitat degradation due to severe lack of water resources, soil erosion and excessive pollutant emission. The improper management of water- environment strategy may not only lead to severe shortage, but also result in environmental degradation even further exacerbated by deforestation and irrigation-induced soil erosion. Therefore, the water managers in study region is responsible for generating a water resources allocation plan (i.e., water management) and environmental policy, with 
consideration of economic development (i.e., agricultural productions), environmental protection (i.e., ecology recovering), social development associated with water safety (i.e., living water assurance) and minimum water deficit as follows:

$\max \tilde{f}=(1)+(2)+(3)$

(1) Net system benefit from irrigation system

$$
\begin{aligned}
& \sum_{m=1}^{4} \sum_{j=1}^{7} D A_{m j} \cdot \tilde{B}_{m j}^{A} \cdot R A_{m j} \\
& -\sum_{k=1}^{3} \sum_{m=1}^{4} \sum_{j=1}^{7} \tilde{T}_{m j}^{A C} \cdot\left(D A_{m j} \cdot R A_{m j}-S A_{k m j}\right) \\
& -\sum_{k=1}^{3} \sum_{m=1}^{2} \sum_{j=1}^{7} p_{k j} \cdot \tilde{C}_{m j}^{A} \cdot S A_{k m j}-\sum_{k=1}^{3} \sum_{m=1}^{4} \sum_{j=1}^{7} \tilde{F}_{m j}^{A C} \cdot \alpha_{m j} \\
& \cdot\left(D A_{m j} \cdot R A_{m j}-S A_{k m j}\right) \cdot\left(N A_{m j}+P A_{m j}+B A_{m j}\right) \\
& -\sum_{k=1}^{3} \sum_{m=1}^{4} \sum_{j=1}^{7} \tilde{F}_{m j}^{A C S} \cdot \alpha_{m j} \cdot\left(D A_{m j} \cdot R A_{m j}-S A_{k m j}\right) \\
& -\sum_{k=1}^{3} \sum_{m=1}^{4} \sum_{j=1}^{7} \tilde{F}_{m j}^{A C W} \cdot \beta_{m j} \cdot\left(D A_{m j} \cdot R A_{m j}-S A_{k m j}\right)
\end{aligned}
$$

The detailed nomenclatures for the variables and parameters are provided in Notation and Subscript. Where model (11b) presents that system benefit from irrigating crops. However, since limited available water resources are allocated for competitive water consumers (i.e., various crops) in study region, water deficits would be occur when water demands are not met, which would result in losses. Meanwhile, there are non-point source pollution discharges (e.g., nitrogen, phosphorus and BOD discharges) jeopardizing to environment due to fertilization. Thus, net system benefit from irrigation system equals to the benefit of crop minus the loss for water deficit and the cost for environmental damage (\$).

(2) Net system benefit from drinking safety

$$
\begin{aligned}
& \sum_{j=1}^{7} D M_{j} \cdot \tilde{B}_{j}^{M}-\sum_{k=1}^{3} \sum_{j=1}^{7} \tilde{T}_{j}^{M C} \cdot\left(D M_{j}-S M_{k j}\right) \\
& -\sum_{k=1}^{3} \sum_{j=1}^{7} p_{k j} \cdot \tilde{C}_{j}^{M} \cdot S M_{j}-\sum_{k=1}^{3} \sum_{j=1}^{7} \tilde{F}_{j}^{M C} \cdot\left(D M_{j}-S M_{k j}\right) \\
& \cdot\left(P M_{j}+N M_{j}+B M_{j}\right)
\end{aligned}
$$

Model (11d) presents that system benefit from drinking safety (living water for farmer), which would be guaranteed firstly. Meanwhile, water deficit and pollution discharges (e.g., nitrogen, phosphorus and BOD discharges) from farmers would result in decreasing of system benefit.
(3) Net system benefit from ecological system

$$
\begin{aligned}
& {\left[\sum_{n=1}^{5} \sum_{j=1}^{7} D E_{n j} \cdot \tilde{B}_{n j}^{E} \cdot R E_{n j}-\sum_{k=1}^{3} \sum_{n=1}^{4} \sum_{j=1}^{7} \tilde{T}_{n j}^{E C} \cdot\left(D E_{n j} \cdot R E_{n j}-S E_{k n j}\right)\right]} \\
& -\sum_{k=1}^{3} \sum_{n=1}^{4} \sum_{j=1}^{7} p_{k j} \cdot \tilde{C}_{n j}^{E} \cdot S E_{n j}+\sum_{k=1}^{3} \sum_{n=1}^{4} \sum_{j=1}^{7} \tilde{F}_{n j}^{E C} \cdot\left(D E_{n j} \cdot R E_{n j}-S E_{k n j}\right) \\
& \cdot\left(\gamma_{P}+\gamma_{N}+\gamma_{B}\right)+\sum_{k=1}^{3} \sum_{n=1}^{4} \sum_{j=1}^{7} \tilde{F}_{n j}^{E C S} \cdot \varphi_{n j} \cdot\left(D E_{n j} \cdot R E_{n j}-S E_{k n j}\right) \\
& +\sum_{k=1}^{3} \sum_{n=1}^{4} \sum_{j=1}^{7} \tilde{F}_{n j}^{E C W} \cdot \mu_{n j} \cdot\left(D E_{n j} \cdot R E_{n j}-S E_{k n j}\right)
\end{aligned}
$$

Model (11d) presents that system benefit from ecological system, which is mainly from ecological plant. Ecological plants can take away excessive pollution discharges (e.g., nitrogen, phosphorus and BOD discharges) due to fertilization, which has a prominent indirect benefit. Meanwhile ecological system can play role of water conservation and soil intention. Moreover, there are numbers of constraints (including inequalities/equalities of water demand, availability, water supply capacity, soil erosion, nitrogen/phosphorus/BOD discharges and technique constraints) are as follows:

(1) Constraints of water availability:

$\tilde{Q}_{j k}=\tilde{R}_{j k}-E_{j}-H_{j}+Q U_{j}$

(2) Constraints of water deficit:

$$
\begin{gathered}
M e\left\{\sum_{k=1}^{3} \sum_{m=1}^{4} \sum_{j=1}^{6}\left(D A_{m j} \cdot R A_{m j}-S A_{k m j}\right)\right. \\
+\sum_{k=1}^{3} \sum_{n=1}^{4} \sum_{j=1}^{6}\left(D E_{n j} \cdot R E_{m j}-S E_{k n j}\right) \\
\left.+\sum_{k=1}^{3} \sum_{j=1}^{6}\left(D M_{j} \cdot R M_{j}-S M_{k j}\right) \leq \tilde{Q}_{j h}\right\} \geq \delta
\end{gathered}
$$

(3) Constraints of water supply capacity:

$$
\begin{aligned}
& \sum_{m=1}^{4} \sum_{j=1}^{6} D A_{m j} \cdot R A_{m j}+\sum_{n=1}^{4} \sum_{j=1}^{6} D E_{n j} \cdot R E_{m j} \\
& \quad+\sum_{j=1}^{6} D M_{j} \leq S C M_{j}
\end{aligned}
$$

(4) Pollution retreatment capacity through ecological mechanism

$$
\begin{aligned}
& \sum_{k=1}^{3} \sum_{n=1}^{4} \sum_{j=1}^{7}\left(D E_{n j} \cdot R E_{n j}-S E_{k n j}\right) \cdot\left(\gamma_{P}+\gamma_{N}+\gamma_{B}\right. \\
& \leq N A P_{k j}+P A P_{k j}+B A P_{k j}
\end{aligned}
$$


(5) Constraints of soil erosion:

$\sum_{m=1}^{4} \sum_{j=1}^{6} D A_{m j} \cdot R A_{m j} \cdot \alpha_{m j}-\sum_{n=1}^{4} \sum_{j=1}^{6} D E_{n j} \cdot R E_{n j} \cdot \beta_{n j} \leq E A_{j}$

(6) Constraints of nitrogen discharge:

$\sum_{k=1}^{3} \sum_{m=1}^{4} \sum_{j=1}^{6}\left(D A_{m j} \cdot R A_{m j}-S A_{k m j}\right) \cdot N A_{m j}$

$+\sum_{k=1}^{3} \sum_{j=1}^{6}\left(D M_{k j} \cdot R A_{k j}-S M_{k j}\right) \cdot N M_{k j}$

$-\sum_{k=1}^{3} \sum_{n=1}^{4} \sum_{j=1}^{6}\left(D E_{n j} \cdot R E_{n j}-S E_{k n j}\right) \cdot \gamma_{N} \leq N A P_{k j}$

(7) Constraints of phosphorus discharge:

$\sum_{k=1}^{3} \sum_{m=1}^{4} \sum_{j=1}^{6}\left(D A_{m j} \cdot R A_{m j}-S A_{k m j}\right) \cdot P A_{m j}$

$-\sum_{k=1}^{3} \sum_{n=1}^{4} \sum_{j=1}^{6}\left(D E_{n j} \cdot R E_{n j}-S E_{k n j}\right) \cdot \gamma_{N}$

$+\sum_{k=1}^{3} \sum_{j=1}^{6}\left(D M_{j} \cdot R A_{j}-S M_{k j}\right) \cdot P M_{k j} \leq P A P_{k j}$

(8) Constraints of BOD discharge:

$\sum_{k=1}^{3} \sum_{m=1}^{4} \sum_{j=1}^{6}\left(D A_{m j} \cdot R A_{m j}-S A_{k m j}\right) \cdot B A_{m j}$

$-\sum_{k=1}^{3} \sum_{n=1}^{4} \sum_{j=1}^{6}\left(D E_{n j} \cdot R E_{n j}-S E_{k n j}\right) \cdot \gamma_{B}$

$+\sum_{k=1}^{3} \sum_{j=1}^{6}\left(D M_{j} \cdot R A_{j}-S M_{k j}\right) \cdot B M_{k j} \leq B A P_{k j}$

(9) Constraints of water usage from living water from farmer:

$\sum_{j=1}^{7} D M_{j} \geq A X M_{j}$

(10) Constraints of irrigation area:

$\sum_{m=1}^{4} \sum_{j=1}^{6} D A_{m j} \leq X D A_{m j}$

(11) Constraints of ecological planting area:

$\sum_{n=1}^{4} \sum_{j=1}^{6} D E_{n j} \leq X D E_{n j}$

(12) Constraints of technique:

$0 \leq C M_{j} \leq B M_{j}, 0 \leq C A_{m j} \leq B A_{m j}, 0 \leq C E_{n j} \leq B E_{n j}$
Constraint (1) presents the mass balance for water resources in a planning period, where water availability equals to water flow minus underground water, then minus evaporation/infiltration loss and normal water requirement of watercourse $\left(\mathrm{m}^{3}\right)$. Constraint (2) presents that water deficits would occur when water demands are not met. Constraint (3) presents that water supply capacity is less than maximum limitation of water supply capacity. Constraint (4) presents ecological effects in this system. Constraints (6)-(8) present pollution discharges would be less than maximum limitation of discharges in study region. Constraint (9) presents that water demands of living water from farmer would be bigger than the minimum water quota. Constraints (10) and (11) present that the scale of land utilization area would be less than maximum limitation of land use. Constraint (12) is non-negativity restrictions.

\subsection{Data acquisition}

In order to obtain accurate predictions of water demands associated with a variety of uncertainties, support vector regression (SVR) technique can be introduced (Dai et al. 2011). In fact, SVR is a set of supervised learning models with associated learning algorithms that analyze data used for classification and regression analysis, which can build a model that assigns new examples to one category or the other, making it a non-probabilistic binary linear classifier. Figure 1 present that prospective water demand can be imported based on machine learning theory, where the regression relationship between prospective water demand and input/import vector can be verified through SVR method (Vapnik 1998; Smola and Schölkopf 2000). Figure 2 illustrates the results of water demand prediction through SVR, where living water of farm, cotton and tamarix are selected as represent users in IS of Kaidukongque River Basin. In the process of predicting, the input data from 2001 to 2010 are regarded as training sets, meanwhile, the data from 2009 to 2014 are deemed as the testing sets (Cherkassky and Ma 2004; Levis and Papageorgiou 2005). Under these situations, perditions of living water of farm, cotton and tamarix from 2015 to 2020 would be obtained. In order to compare the deviation of the observation and prediction, the $\varepsilon$ can be introduced. In general, the $\varepsilon$ is estimated as $5-10 \%$ of prediction value, which can formulate an interval to reflect the predication accuracy. In this study, the fitting accuracy would exceed $89.32 \%$.

Table 1 presents the data economic data such as net benefit and loss of unit water based on the calculation of regional statistical yearbook indirectly (SYXUAR 2010). In fact, due to the data deficiency, the economic data such 
(a) Living water of farmer

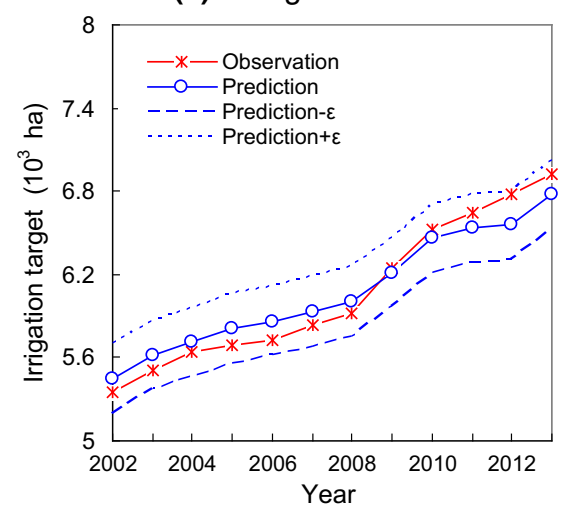

(b) Cotton

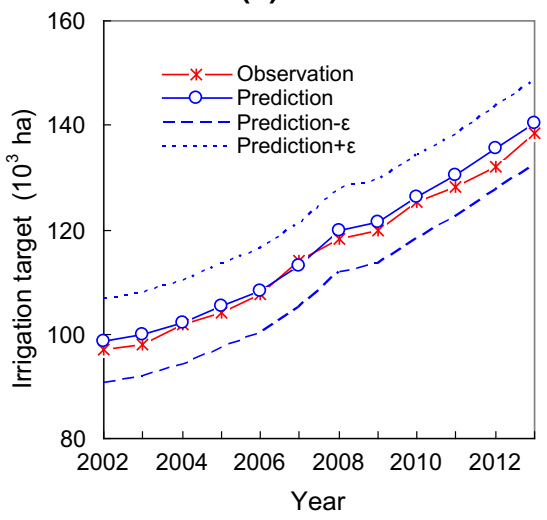

(c) Tamarix

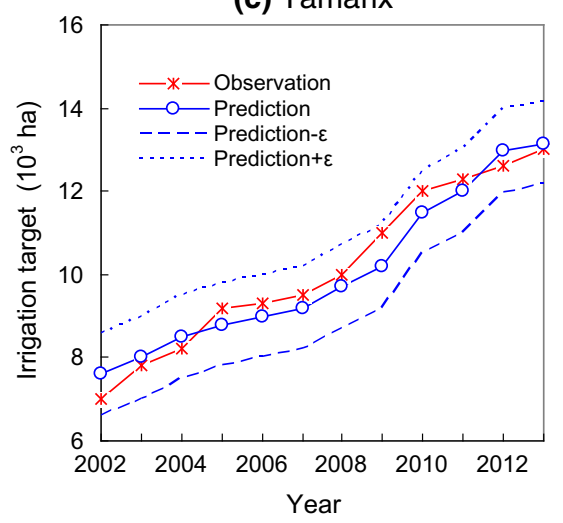

Fig. 2 Prediction of water demand expectation

as net benefit, loss of water deficit and cost of retreatment can be expressed as fuzzy sets. In general, we can define a threshold based on analysis of available data; then we can calculate the fuzzy numbers of the economic data through expert evaluation method or the empirical approach. Table 2 present total water availability and probability in study region. Based on previous works, the rate of water and soil erosion in this region is 1.6; meanwhile content of nitrogen/phosphorus/BOD discharges per water consumption would be $0.12,0.5,0.07 \%$. With aim to analyze ecological effects and benefits from various environmental policies in a ecological irrigation system, five cases associated with water allocation policies are set (as shown in Table 3).

\section{Results and discussion}

\subsection{Irrigation area and water allocation under various polices (cases)}

In this study, sinceMe $\{\xi \leq r\}=N e c\{\xi \leq r\}+\lambda($ Pos $\{\xi \leq r\}-N e c\{\xi \leq r\})$, when $\lambda=0.5$ and $\delta=1$, the measure Me can be equal to measure $\mathrm{Cr}$, which means decision maker would have a compromise attitude. The solutions for the objective-function value and were obtained as lower/upper approximation value (denoted as "LAV"/"UAV") through solving the SRAWM model. Figure 3 provides water deficit area of agricultural corps and ecological plants in study region under cases 1 and 5 . The results show that deficit area would vary with different cases (policies). Water deficit area of agricultural crops would be lower under case 1 , while the opposite results happen under case 5. For example, when water availability is high-level, lower and upper approximation value of vegetable deficit area in Kuerle county would be 0.25 and $0.74 \times 10^{3}$ ha under case 1 , while they would be 0.37 and
$0.79 \times 10^{3}$ ha under case 5 . Meanwhile, since irrigation system and ecological system are competitive water consumers in water usage, more water have been allocated to ecological plants can support exertion of ecological function to sustain better ecological environment, while leading more deficit in irrigation; vice versa. Since poor water availabilities in study region due to changes of climate/ environment and developments of social-economy, limited available water can be satisfied the water consumers who have highest benefits firstly. Thus, water deficits would occur when water demands are not met. In study region, the net benefit of living water is highest among various water consumers, which can be guarded firstly. Then, agricultural activities and ecological protection would can be deemed as water competitors in water consumption. It indicates that, if the lower-benefit water consumer should consider reduce water demand to confront penalty of water shortage and cost of environmental retreatment. Figure 4 shows water deficits among various agricultural crops under cases 1 and 5 when $\lambda=0.5$ and $\delta=1$. The results indicate that deficit areas (based on Fig. 3) would lead different water deficits. The results present deficit area would vary with different water-availability levels over a two-stage context. For example, under case 1, LAV and UAV of deficit area for cotton in Yanqi county would be 1.36 and $14.78 \times 10^{3}$ ha when water-availability level is low; while they would be 1.09 and $13.02 \times 10^{3}$ ha when water-availability level is high. It implies that enormous deficit occur in dry season, while deficit area would decrease in wet season.

Since shortage would occur if the pre-regulated target could not be satisfied, thus, the actual water allocation would equal to pre-regulated target minus the probabilistic shortage. Figure 5 presents total water allocations among different regions under case 1 when $\delta$-level (i.e., confidence level) is varied and $\lambda$-level (i.e., optimistic-pessimistic adjusting parameter) is 1 . The results present as follows: (a) in comparison of total water allocations, 
Table 1 Economic data

\begin{tabular}{|c|c|c|c|c|c|c|c|}
\hline & \multicolumn{7}{|l|}{ District } \\
\hline & Kuerla & Yanqi & Hejing & Heshuo & Bohu & Yuli & Luntai \\
\hline \multicolumn{8}{|c|}{ Net benefits (US $\$ / 10^{3} \mathrm{~m}^{3}$ ) } \\
\hline $\begin{array}{l}\text { Living water } \\
\text { for farmer }\end{array}$ & $(531,585,621)$ & $(380,401,429)$ & $(302,336,458)$ & $(348,386,396)$ & $(321,357,378)$ & $(331,368,389)$ & $(380,400,423)$ \\
\hline \multicolumn{8}{|c|}{ Agriculture crops } \\
\hline Wheat & $(312,325,368)$ & $(311,338,365)$ & $(319,342,369)$ & $(318,335,351)$ & $(312,344,357)$ & $(313,336,359)$ & $(315,328,341)$ \\
\hline Cotton & $(298,321,353)$ & $(283,325,357)$ & $(282,285,296)$ & $(211,233,256)$ & $(254,256,279)$ & $(245,268,283)$ & $(221,224,239)$ \\
\hline Oil plant & $(292,325,348)$ & $(223,236,249)$ & $(221,234,247)$ & $(210,223,235)$ & $(222,235,249)$ & $(214,237,250)$ & $(223,247,258)$ \\
\hline Vegetable & $(365,368,371)$ & $(361,373,385)$ & $(366,378,390)$ & $(322,346,369)$ & $(322,346,369)$ & $(324,349,372)$ & $(313,334,351)$ \\
\hline \multicolumn{8}{|c|}{ Ecological plants } \\
\hline Medicago & $(99,104,110)$ & $(88,92,94)$ & $(82,86,91)$ & $(84,88,93)$ & $(81,94,99)$ & $(84,87,91)$ & $(88,91,95)$ \\
\hline Populus & $(82,87,94)$ & $(77,79,82)$ & $(81,84,89)$ & $(72,77,82)$ & $(75,78,80)$ & $(77,79,84)$ & $(72,76,79)$ \\
\hline Tamarix & $(66,68,72)$ & $(68,73,75)$ & $(69,72,76)$ & $(70,72,76)$ & $(68,72,76)$ & $(77,79,83)$ & $(68,74,78)$ \\
\hline Alhagi & $(62,64,69)$ & $(61,64,67)$ & $(63,65,68)$ & $(64,67,70)$ & $(65,68,72)$ & $(62,66,69)$ & $(61,65,70)$ \\
\hline Other & $(86,89,94)$ & $(88,92,96)$ & $(89,94,99)$ & $(88.92,96)$ & $(87,91,97)$ & $(85,88,92)$ & $(84,87,89)$ \\
\hline \multicolumn{8}{|c|}{ Loss of water deficit $\left(10^{3}\right.$ US $\left.\$ / 10^{3} \mathrm{~m}^{3}\right)$} \\
\hline $\begin{array}{l}\text { Living water } \\
\text { for farmer }\end{array}$ & $(637,690,743)$ & $(456,485,523)$ & $(362,432,521)$ & $(412,463,498)$ & $(481,535,567)$ & $(397.2,434,489)$ & $(456,489,523)$ \\
\hline \multicolumn{8}{|c|}{ Agriculture crops } \\
\hline Wheat & $(374,423,489)$ & $(370,405,438)$ & $(382,410,442)$ & $(365,402,421)$ & $(374,412,428)$ & $(375,403,430)$ & $(378,393,409)$ \\
\hline Cotton & $(357,385,424)$ & $(339,390,428)$ & $(338,342,355)$ & $(253,279,307)$ & $(304,307,334)$ & $(294,323,339)$ & $(267,289,312)$ \\
\hline Oil plant & $(350,398,417)$ & $(267,289,299)$ & $(264,280,297)$ & $(262,276,282)$ & $(266,274,332)$ & $(294,321,345)$ & $(269,297,332)$ \\
\hline Vegetable & $(438,442,456)$ & $(436,447,462)$ & $(439,453,468)$ & $(386,415,442)$ & $(386,415,442)$ & $(388,418,446)$ & $(375,401,421)$ \\
\hline \multicolumn{8}{|c|}{ Ecological plants } \\
\hline Medicago & $(118,124,138)$ & $(104,112,116)$ & $(98,103,110)$ & $(101,108,114)$ & $(97,116,118)$ & $(101,105,110)$ & $(108,109,114)$ \\
\hline Populus & $(96,105,116)$ & $(92,95,102)$ & $(94,101,109)$ & $(86,92,99)$ & $(89,94,100)$ & $(92,97,102)$ & $(82,96,100)$ \\
\hline Tamarix & $(79,83,86)$ & $(83,88,92)$ & $(84,88,90)$ & $(86,87,91)$ & $(81,86,91)$ & $(92,97,101)$ & $(82,89,94)$ \\
\hline Alhagi & $(74,79,84)$ & $(72,79,82)$ & $(73,77,80)$ & $(79,82,88)$ & $(80,84,88)$ & $(73,78,81)$ & $(72,76,79)$ \\
\hline Other & $(72,78,82)$ & $(75,79,84)$ & $(76,81,88)$ & $(75,80,87)$ & $(104,109,114)$ & $(102,106,110)$ & $(101,105,108)$ \\
\hline \multicolumn{8}{|c|}{ Cost of sewage retreatment (US $\$ / 10^{3} \mathrm{~m}^{3}$ ) } \\
\hline $\begin{array}{l}\text { Living water } \\
\text { for farmer }\end{array}$ & $(796,858,680)$ & $(570,610,670)$ & $(450,530,680)$ & $(522,579,594)$ & $(481,535,567)$ & $(496,552,583.5)$ & $(570,600,635)$ \\
\hline $\begin{array}{l}\text { Agriculture } \\
\text { crops }\end{array}$ & $(448,489,512)$ & $(402,423,456)$ & $(410,434,489)$ & $(380,399,424)$ & $(400,445,490)$ & $(395,434,478)$ & $(383,412,445)$ \\
\hline $\begin{array}{l}\text { Ecological } \\
\text { plants }\end{array}$ & $(149,161,189)$ & $(134,145, ' 51)$ & $(135,140,148)$ & $(138,147,151)$ & $(142,148,155)$ & $(131,138,143)$ & $(136,142,146)$ \\
\hline
\end{tabular}

Table 2 Probability levels and total water availabilities

\begin{tabular}{llll}
\hline & Flow levels & Probabilities & Water availabilities $\left(10^{6} \mathrm{~m}^{3}\right)$ \\
\hline An irrigation system (IS) & Low & 0.512 & $(12.54,12.87,13.39)$ \\
& Medium & 0.350 & $(13.47,14.98,15.48)$ \\
& High & 0.138 & $(15.54,16.23,17.19)$ \\
\hline
\end{tabular}

irrigation deemed as the largest water conservation in IS, which is confronting severe water shortage; (b) in this IS, living water for farmer would occupy low rate of water availability, meanwhile rare deficit would occur. (c) although ecological consumers would take up $5.62 \%$ water availability, which would reduce water to irrigation directly. However, the ecological function of IS would generate higher indirect benefit (e.g., reduction of pollution 
Table 3 Policy scenarios

Fig. 3 Deficit areas among various water consumers in the ecological irrigations district under cases 1 and 5 when $\lambda=0.5$ and $\delta=1$
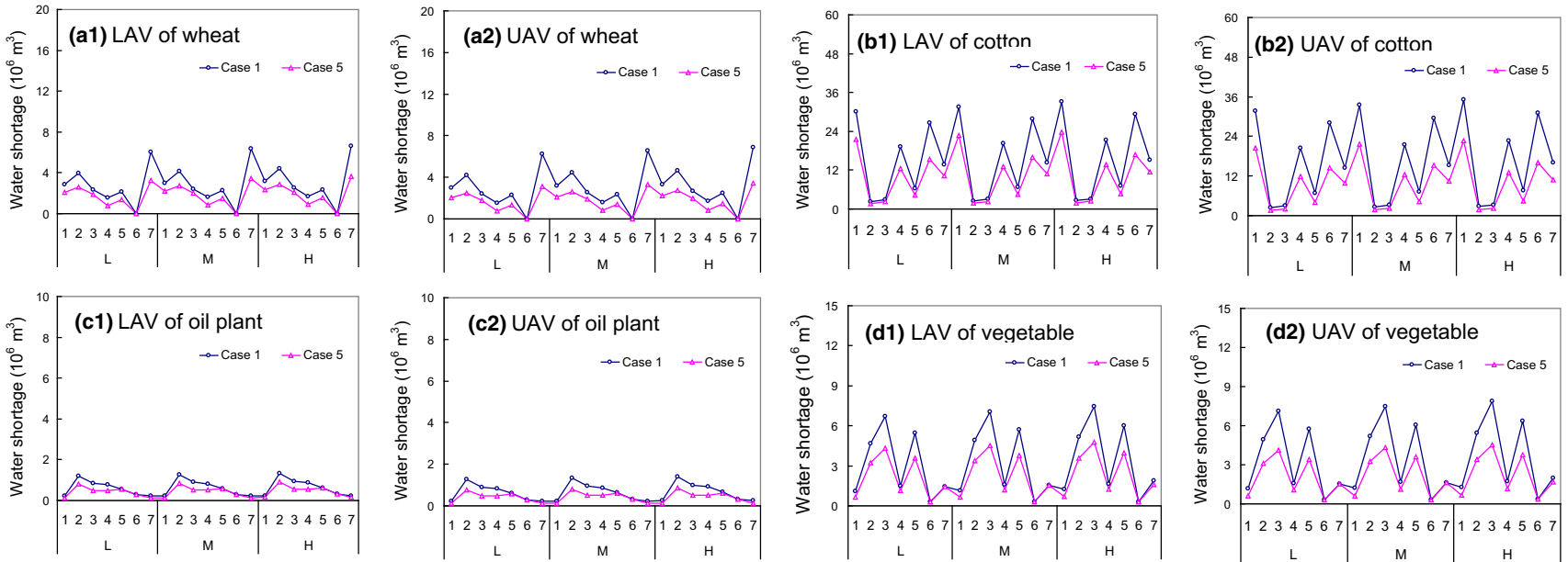

Fig. 4 Water deficits among various agricultural crops under cases 1 and 5 when $\lambda=0.5$ and $\delta=1$ ( 1 denote as Kuerla county, 2 denote as Yanqi county, 3 denote as Hejing county, 4 denote as Heshuo

discharges, prevention of desertification and soil/water conservation) to agricultural irrigation. (d) the results indicate that water allocations would vary with various
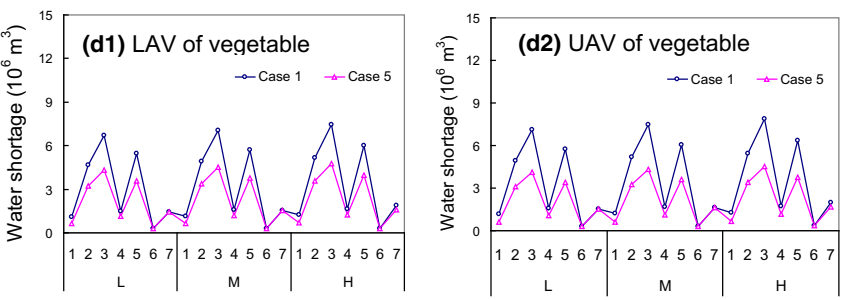

county, 5 denote as Bohu county, 6 denote as Yuli county, 7 denote as Luntai county)

$\delta$-levels. The higher $\delta$-levels would generate higher water shortages and lower water allocations; vice versa. For example, under case 1, when inflow is low, LAV and UAV
Scenario assumption

Scenario 1 with $0 \%$ mitigation of irrigation water

Scenario 2 with $5 \%$ mitigation of irrigation water for ecological use Scenario 3 with $10 \%$ mitigation of irrigation water for ecological use Scenario 4 with $15 \%$ mitigation of irrigation water for ecological use Scenario 5 with $20 \%$ mitigation of irrigation water for ecological use
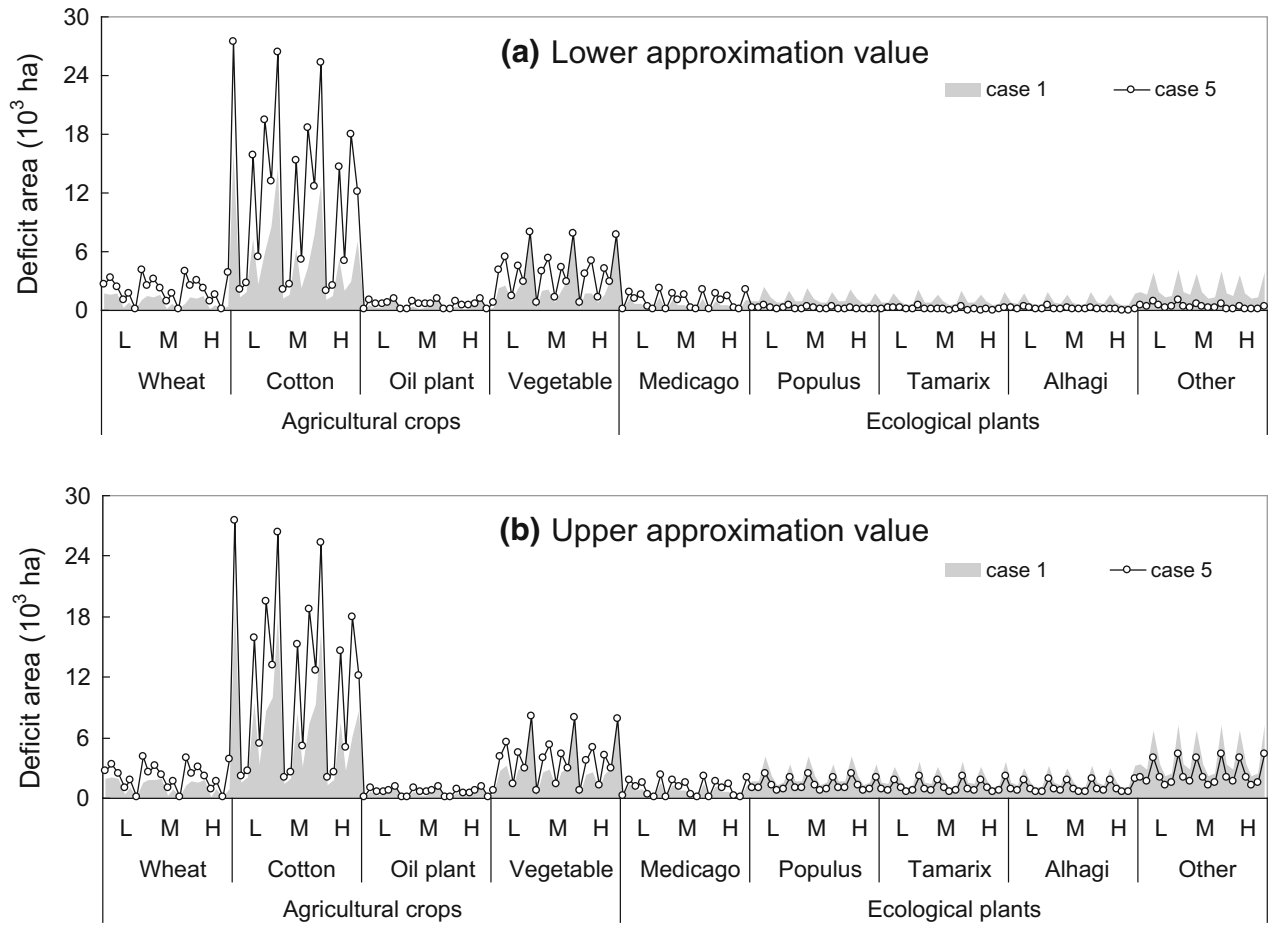

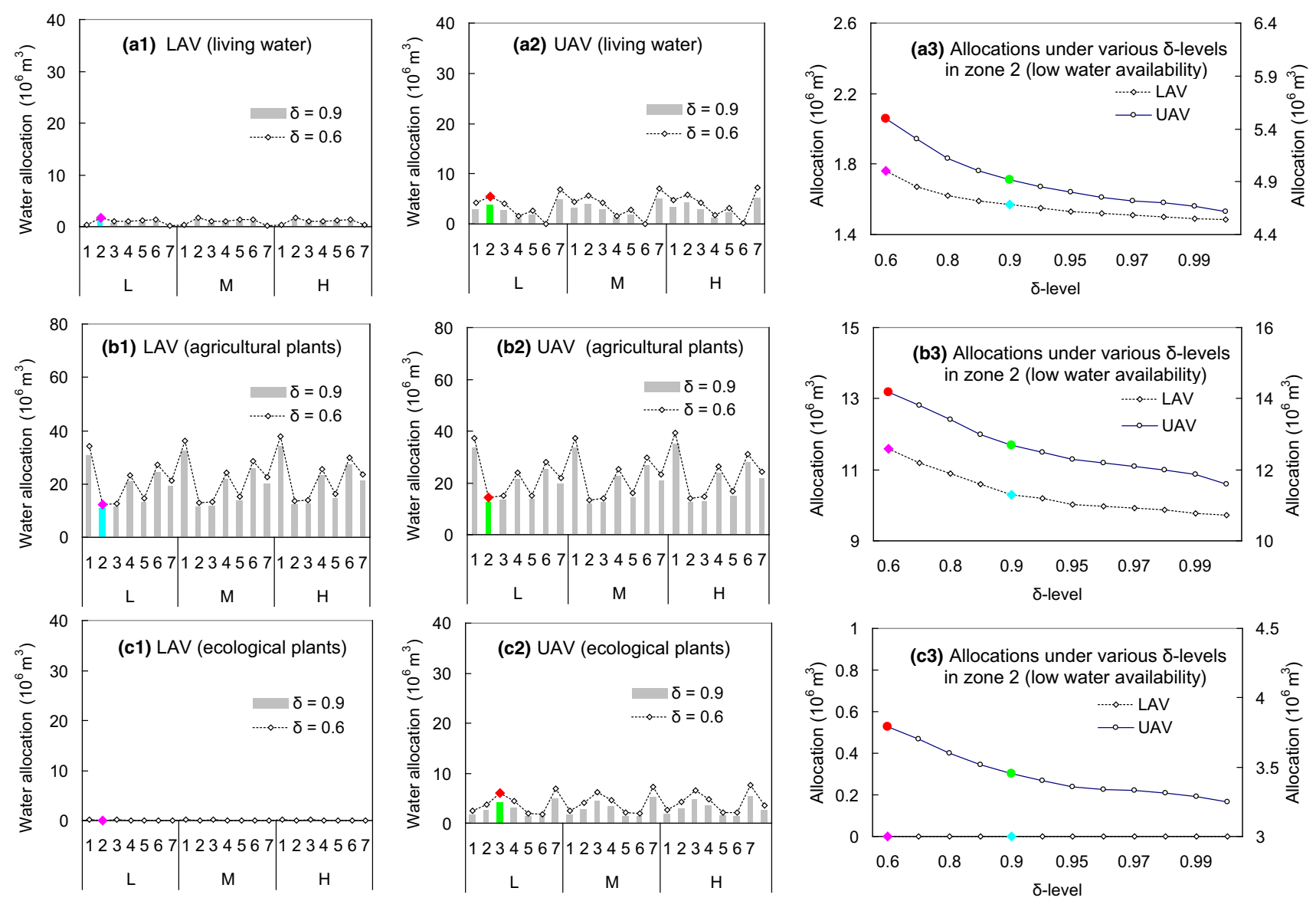

Fig. 5 Total water allocations among different regions under various $\delta$-levels when $\lambda$-level is 1 (case 1 )

of living water shortages in Yanqi county water would be 0.26 and $0.32 \times 10^{6} \mathrm{~m}^{3}$ under $\alpha=0.6$, which result in actual allocations would be 1.79 and $5.32 \times 10^{6} \mathrm{~m}^{3}(\mathrm{LAV}$ and UAV); while they would be 1.62 and $4.74 \times 10^{6} \mathrm{~m}^{3}$ under $\alpha=0.9$. It implies that water allocation corresponding to lower $\alpha$-level is bigger than that with higher one, since lower $\alpha$-levels generate lower credibility-satisfactions and higher violation risks in a planning system.

\subsection{Ecological effects under various cases}

In the SRAWM model, five policies cases corresponding to various environment protection targets and ecological effects are set (as shown in Table 3). Among of them, case 1 is current water-environment plan, which corresponding to the lowest ecological effects. Case 2-5 mean that water for irrigation crops would be lessen for ecological use, which can enhance the ecological function (e.g., pollution discharges purification, soil intention and water conservation). Figure 6 shows ecological effects under cases 1, 3 and 5 when $\lambda$-level is 0.5 and $\delta$-level is 1 . In study region, water can be deemed as an effective linkage between human activity and environmental protection, where water allocation plan would influence the exertion of social economic function (i.e., agricultural crops) and ecological function (i.e., ecological plants) directly. It indicates that more water allocated to ecological use would result in a higher ecological effect; correspondingly, less water allocated to irrigation plants would lead to a higher water deficit; vice versa. For instance, when water availability is low, the LAV amount of purified TN, TP and BOD discharges through ecological mechanism would be 21.58, $10.64,146.26$ ton under case 1 , while they would be 29.3 , 15.97, 170.61 ton under case 5. Figure 7 shows the relationship among deficit areas, water allocations and ecological effects under various cases when $\lambda$-level is 0.5 and $\delta$-level is 1 . The results present higher deficit area in irrigation crops (e.g., case 5) is corresponding to higher ecological effect in IS, which can reduce the rate of nitrogen discharge, phosphorus discharge and water/soil erosion $16.5,23.1$, and $12.1 \%$ at highest (when water availability is high). It implies that more water being allocated to ecological plants would generate higher ecological function, which would generate maximum deficit of agricultural irrigation (e.g., case 5). Figure 8 shows that ecological effects and changed system benefits under different cases 
Fig. 6 Ecological effects under cases 1,3 and 5 when $\lambda$-level is 0.5 and $\delta$-level is 1

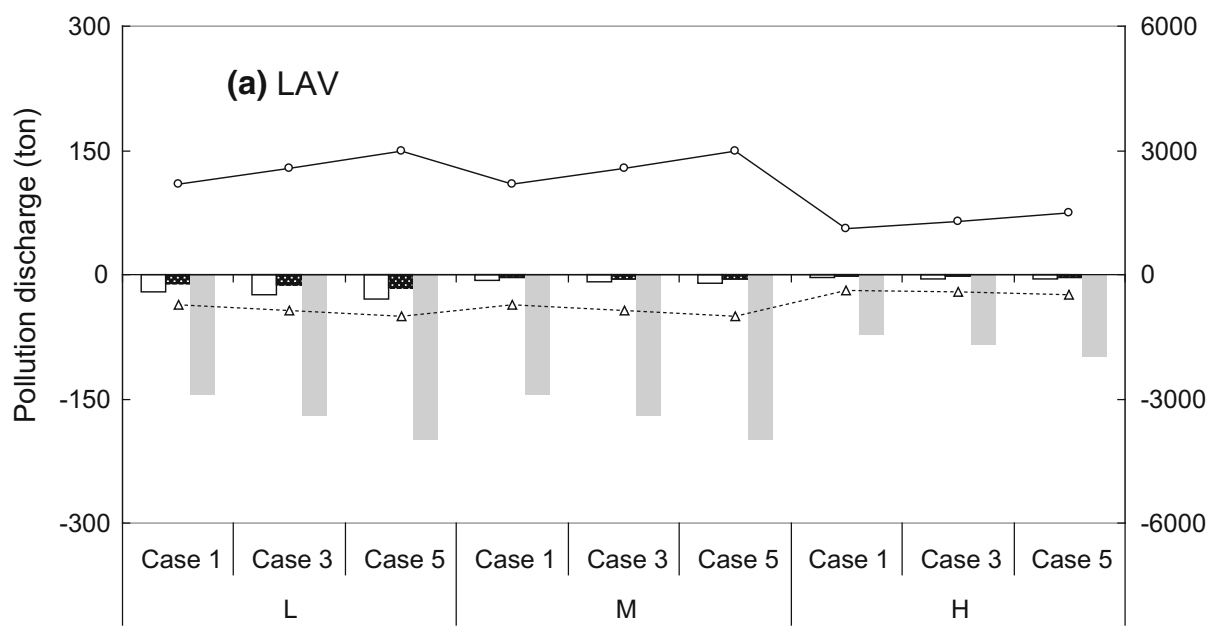

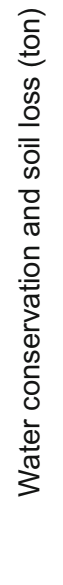

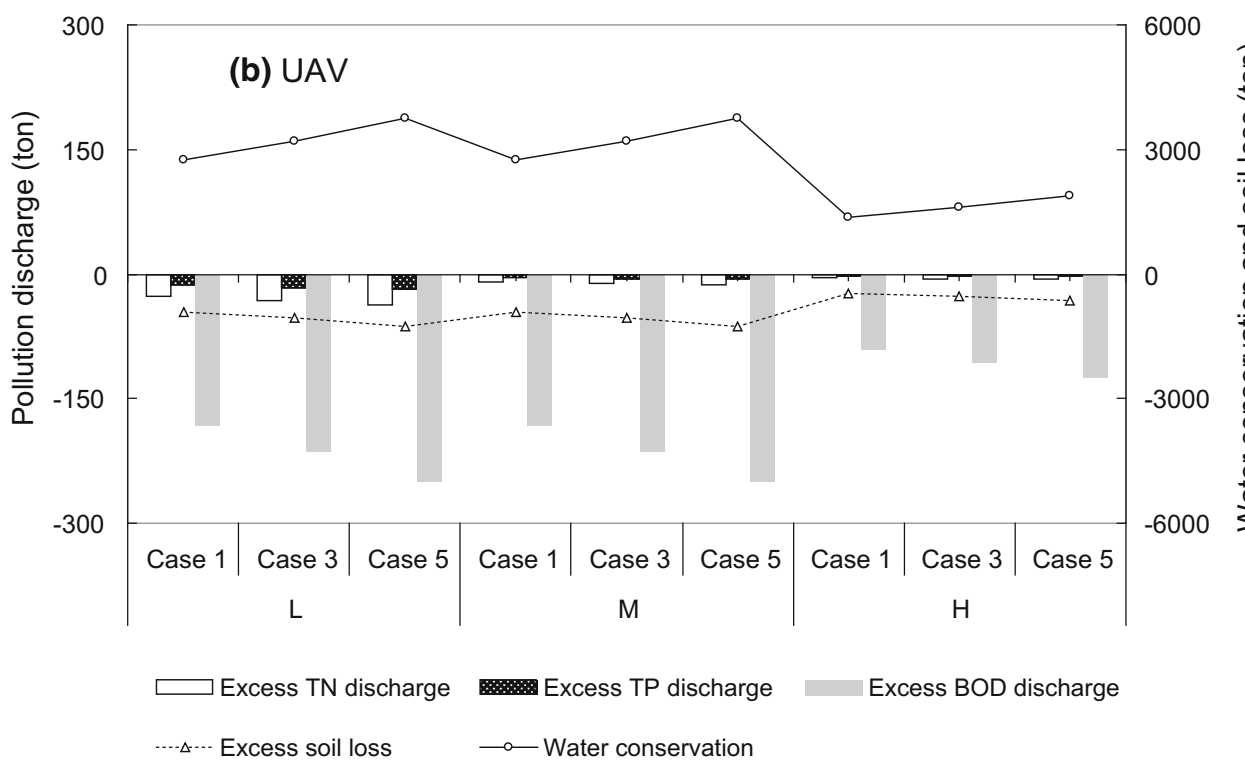

when $\delta$ - and $\lambda$-level are varied. Since IS can reverse pollution discharges through their self-purification capacity meanwhile play a role of soil and water conservation, which result in an increased system benefit. For example, when $\delta$-level is 0.6 and $\lambda$-level is 0.9 , comparing to case 1 , LAV and UAV of increased system benefits would be 0.41 and $0.49 \times 10^{9} \$$ under case 2 , while they would be 0.86 and $1.12 \times 10^{9} \$$ under case 4 . It implies that the increased benefits from ecological mechanism are higher than losses of water deficits in irrigative actives. Thus, the total system benefits present an increasing tendency with various ecological effects (corresponding to different policies).

\subsection{System benefit and risk sensitive analysis}

Figure 9 shows system benefits of various cases under different $\delta$ - and $\lambda$-level. Through solving the SRAWM model, results present as follows: (a) Fig. 9a presents system benefits would varied with various cases corresponding to different ecological effects. System benefit would be increased with ecological effects, where higher ecological levels would result in higher system benefits, vice versa. (b) Fig. 9b show that system benefits would increase with the $\lambda$ value. For example, under case 1 , when $\delta$ is 0.6 , the LAV of system benefits would be an increased tendency (from 0.25 to $0.63 \times 10^{9} \$$ ) when $\lambda$-levels are from 0.1 to 0.99 ; meanwhile, the UAV of system benefits would be from 0.28 to $0.72 \times 10^{6} \$$. It implies that a decision with compromised optimistic-pessimistic attitude would be obtained moderate results when $\lambda$-level approaches a middle value. Thus, tradeoff between optimistic and pessimistic attitude of decision makers would generate a robust risk control in decision making processes; (c) Fig. 9c presents that system benefits would decrease 

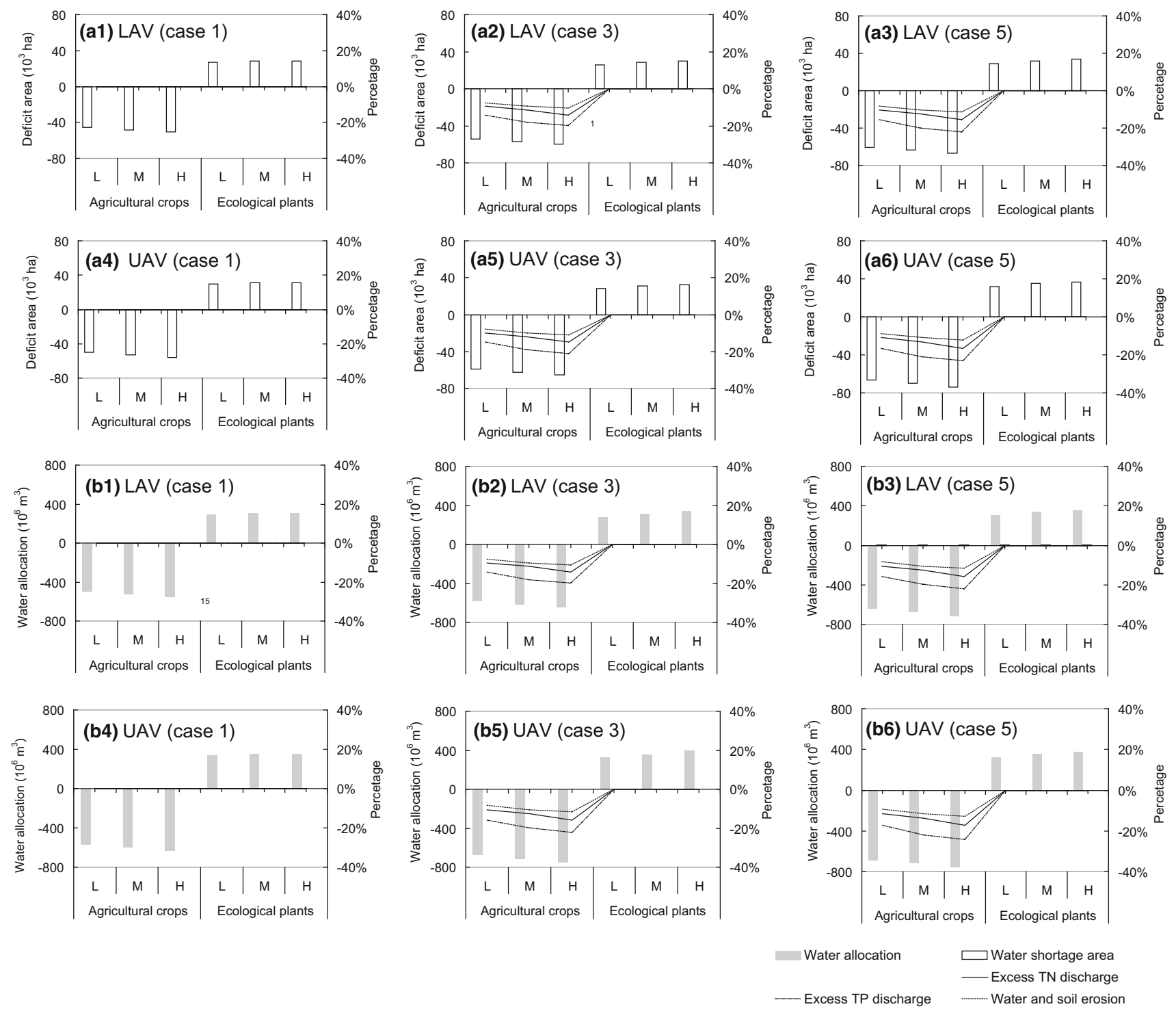

Fig. 7 Relationships among deficit areas, water allocations and ecological effects under various cases when $\lambda$-level is 0.5 and $\delta$-level is 1

Fig. 8 Ecological effects and changes of system benefits under different cases when $\delta$ and $\lambda$-level are varied

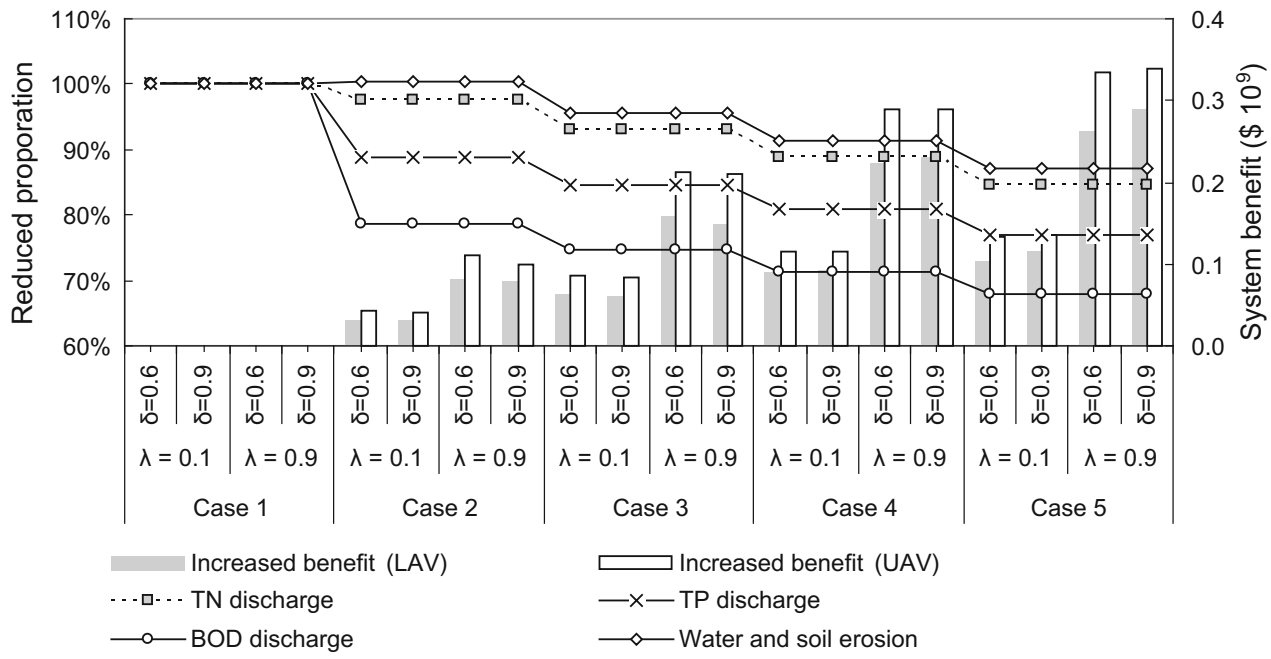


Fig. 9 System benefits of various cases under different $\delta$ and $\lambda$-level
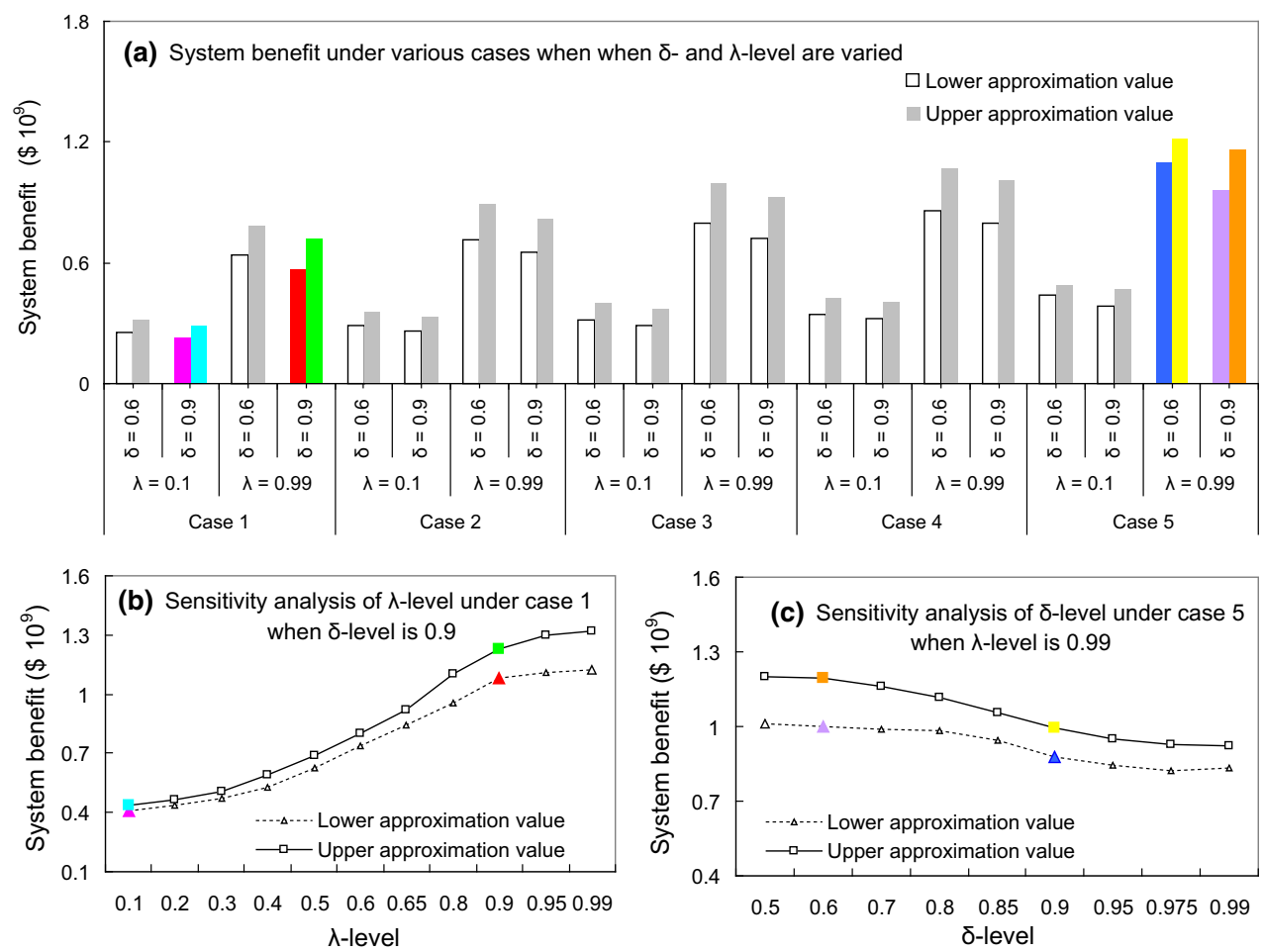

with different $\delta$-levels. For example, under case 5 , when $\lambda$ is 0.99 , the LAV of system benefit would be a decreased trend (from 1.13 to $0.96 \times 10^{9} \$$ ), meanwhile the UAV of system benefits would be from 1.22 to $1.16 \times 10^{6} \$$. Thus, it indicates that a lower $\delta$-level (confidence level) of water availability led a raised risk level, which would generate a decreased system benefit. From the above results, interactive results integrating optimistic-pessimistic attitudes and the confidence levels can be obtained, where interval solutions can give the decision maker upper and lower bounds of the optimal decision. Based on more information under fuzzy uncertainties, decision maker can hold optimistic attitudes to choose a bigger $\lambda$ value in IS plan, while they would be very cautious to choose a greater confidence level.

\section{Discussion}

On base of calculated results, numbers of findings can be disclosed as follows: Firstly, although agricultural production occupies about $95 \%$ water resources in this basin, severe water shortage would often occur. The causes of water deficit would be unscientific irrigation plan, behindhand irrigation regime, extensive pattern of water usage and unreasonable risk option excepting for characteristic of aridity; in addition, shrunk water availability due to water pollution and environmental degradation would be an important reason for water deficit. All above phenomenon have brought negative effects on integrity of social-economic and eco-environmental development in this arid region. Secondly, the results indicate that ecological function can not only bring about indirect benefit to IS, but also acquire long-term return such as environmental recovery. For example, exertion of self-purification capacity in IS can transfer pollution discharges into harmless ingredients autonomously, which can reduce costs of sewage retreatment and increase economic benefits. Thirdly, trade-off of water consumption between ecological plants and agricultural crops would attract the attentions of managers, which can help decision makers generating optimal irrigation plans with consideration of water usage, pollution control and sustainable irrigation. Fourthly, it discovers that optimistic and pessimistic attitudes of decision makers can affect irrigation plans directly. A compromise of optimistic and pessimistic can support generating an eclectic decision that fully reflects risk performance of decision maker. Water shortage/deficit area can be adjusted through introducing rational satisfaction levels, optimistic-pessimistic adjust factors. Fifthly, the irrigation program and fertilization regime of this region is relative backward, where inefficient water usage and excessive pollution discharges would be adverse to sustainability of study region. Therefore, corresponding suggestions for decision makers can be as follows: (a) adjustment of local water-usage structure between agricultural activities and ecological (environmental) protections could lessen water shortages, environmental detriments and 
improve system benefits, as well as satisfying the local demand of drinking security, food safety and environmental protection. (b) strategy analysis associated with ecological effects (e.g., pollution reduction, water/soil conservation, interception of rainfall, alleviation of stalinization, prevention of desertification) can be examined to support planning a ecological irrigation problem sustainably; (c) the efficiency of water-usage and pollutant retreatment from water utilizing process should be promoted. (d) consciousness of risk should be taken to enhance the robustness of irrigation plans in IS. (e) advanced irrigation regime and scientific fertilization regime should be carried out based on integrated needs for crop irrigation and environment requirement. Meanwhile, water saving technology (e.g., drop irrigation) should be considered.

\section{Conclusions}

In this study, a stochastic rough-approximation with optimistic and pessimistic option method (SRAWM) has been developed for planning water management and environmental policies in an IS under uncertainty. The proposed SRAWM has advantages as follows: (a) SRAWM can deal with objective and subjective uncertainties presented fuzzy sets that exist in constraints and objective function; (b) risk preference of decision maker expressed as optimistic-pessimistic attitude can be handled by the advanced measure $\mathrm{Me}$, which can support decision maker to make a robust decision against adventurous and conservative choice in an IS planning; (c) it can transfer a fuzziness problem into a lower/upper approximation value by RST to make results more conveniently to decision makers; (d) the SVR technique embedded into SRAWM can predict water demand more accurately with consideration of various influence factors, which provides a linkage between simulation and optimization techniques to reflect dynamic, interactive, and uncertain characteristics of the irrigation system. However, in a practical IS, multiple processes and multiple factors (e.g., the diversity of system components, the dynamic transformation of pollution discharges and the temporal/ spatial variations of water availabilities) would generate more uncertain features; meanwhile interactions of these uncertainties would enhance the complexities of decision making. Thus, numbers of robust optimization techniques should be applied into a SRAWM framework in the future research, which is beneficial to improve the capacity of tackling multiple formats of uncertainties, as well as promoting realistic application to IS planning.

Acknowledgements This research was supported by the Start Project of Young Teacher of CUEB (Grant No. 00291762791008) and
National Key Research Development Program of China (2016YFC0502803 and 2016YFA0601502). The authors are grateful to the editors and the anonymous reviewers for their insightful comments and suggestions.

\section{References}

Bekri E, Disse M, Yannopoulos P (2015) Optimizing water allocation under uncertain system conditions for water and agriculture future scenarios in Alfeios River Basin (Greece)-Part B: Fuzzyboundary intervals combined with multi-stage stochastic programming model. Stoch Environ Res Risk Assess 7:6427-6466

Cherkassky V, Ma Y (2004) Practical selection of SVM parameters and noise estimation for SVM regression. Neural Netw 17:113-126

Dai C, Li YP, Huang GH (2011) A two-stage support-vectorregression optimization model for municipal solid waste management-A case study of Beijing, China. J Environ Manage 92:3023-3037

Huang GH, Loucks DP (2000) An inexact two-stage stochastic programming model for water resources management under uncertainty. Civ Eng Environ Syst 17:95-118

Huang Y, Li YP, Chen X (2013) A multistage simulation-based optimization model for water resources management in Tarim River Basin, China. Stoch Environ Res Risk Assess 27:147-158

Lau HCW, Jiang ZZ, Ip WH, Wang D (2010) A credibility-based fuzzy location model with Hurwicz criteria for the design of distribution systems in B2C e-commerce. Comput Ind Eng 59:873-886

Lavee D (2010) The effect of water supply uncertainty on farmers' choice of crop portfolio. Agr Water Manag 97:1847-1854

Levis AA, Papageorgiou LG (2005) Customer demand forecasting via support vector regression analysis. Chem Eng Res Des 83:1009-1018

Li YP, Huang GH (2011) Planning agricultural water resources system associated with Fuzzy and random features. J Am Water Resour As 47:841-860

Li YP, Huang GH, Nie SL (2006) An interval-parameter multistage stochastic programming model for water resources management under uncertainty. Adv Water Resour 29:776-789

Li M, Guo P, Fang SQ (2013) An inexact fuzzy parameter two-stage stochastic programming model for irrigation water allocation under uncertainty. Stoch Environ Res Risk Assess 27:1441-1452

Liu B, Liu YK (2002) Expected value of fuzzy variable and fuzzy expected value models. IEEE T Fuzzy Syst 10:45-50

Lopez-Pomares A, Lopez-Iborra GM, Martín-Cantarino C (2015) Irrigation canals in a semi-arid agricultural landscape surrounded by Wetlands: their role as a habitat for birds during the breeding season. J Arid Environ 118:28-36

Mohammad AG, Adam MA (2010) The impact of vegetative cover type on runoff and soil erosion under different land uses. CATENA 81:97-103

Noori R, Abdoli MA, Ghasrodashti AA, Ghazizade MJ (2009) Prediction of municipal solid waste generation with combination of support vector machine and principal component analysis: a case study of Mashhad. Environ Pro Sustain 28:249-258

Pawlak Z (1998) Granularity of knowledge,indiscernibility and rough sets, In: Proceedings of 1998 IEEE International Conference on Fuzzy Systems 1, pp. 106-110

Smola AJ, Schölkopf B (2000) A tutorial on support vector regression. Stat Comput 14:199-222

Steffens K, Larsbo M, Moeys J, Jarvis N, Lewan E (2012) Predicting pesticide leaching under climate change: importance of model 
structure and parameter uncertainty. Agr Ecosyst Environ 172:24-34

The statistical yearbook of Xinjiang Uygur Autonomous Region in Uygur Autonomous Region (SYXUAR) (2010) China. 2011

The statistical yearbook of Xinjiang Uygur Autonomous Region in Uygur Autonomous Region (SYXUAR) (2013) China. 2014

Tilman D, Cassman KG, Matson PA, Naylor R, Polasky S (2002) Agricultural sustainability and intensive production practices. Nature 418:671-677

Trumbo CW, McComa KA (2003) The function of credibility in information processing for risk perception. Risk Anal 23:343-353

Vapnik VN (1998) Statistical Learning Theory. John Wiley and Sons, New York

Wei Y, White R, Hu K, Willett I (2010) Valuing the environmental externalities of oasis farming in Left Banner, Alxa, China. Ecol Econ 69:2151-2157
Wen M, Iwamura K (2008) Fuzzy facility location-allocation problem under the Hurwicz criterion. Eur J Oper Res 184:627-635

$\mathrm{Xu}$ J, Zhou X (2013) Approximation based fuzzy multi-objective models with expected objectives and chance constraints: Application to earth-rock work allocation. Inform Sci 238:75-95

Zadeh LA (1965) Information and control. Fuzzy sets 8:338-353

Zeng XT, Li YP, Huang W, Bao AM, Chen X (2014) Two-stage credibility-constrained programming with Hurwicz criterion (TCP-CH) for planning water resources management. Eng Appl Artif Intell 35:164-175

Zeng X, Yang XL, Yu LY, Chen HL (2015) A mix inexact-quadratic fuzzy water resources management model of floodplain (IQTWMMF) for regional sustainable development of Dahuangbaowa, China. Water 7:2771-2795 